Ezgi Kaya*

\title{
Gender wage gap across the distribution: What is the role of within- and between-firm effects?
}

\begin{abstract}
This paper studies the role of within- and between-firm effects on the gender wage gap (GWG) Using linked employer-employee data for Turkey for 2006 and 2014, we show that the wage gap among comparable men and women is much wider within establishments than between establishments. Our distributional analysis shows a more pronounced gap among highly paid workers, consistent with the presence of a glass-ceiling effect. This effect, however, is more apparent within establishments than between establishments, and it is the former that drives the economy-wide glass ceiling that women face. We also find that between 2006 and 2014, the GWG in Turkey widened at all points in the wage distribution, and that this widening was more pronounced within establishments than between establishments.
\end{abstract}

$\begin{array}{ll}\text { Current version: } & \begin{array}{l}\text { June 15, } 2021 \\ \text { Keywords: }\end{array} \\ & \begin{array}{l}\text { gender wage gap, within- and between-establishments, } \\ \text { wage distribution }\end{array} \\ \text { JEL codes: } & \text { J16, J31, J71 } \\ \text { Corresponding author: } & \begin{array}{l}\text { Ezgi Kaya } \\ \text { KayaE@cardiff.ac.uk }\end{array}\end{array}$

Cardiff Business School, Cardiff University, Aberconway Building, Colum Drive, Cardiff, CF10 3EU, UK. E-mail: KayaE@cardiff.ac.uk.

(c) The Author(s). 2021. Open Access This article is distributed under the terms of the Creative Commons Attribution 4.0 International License (http://creativecommons.org/licenses/by/4.0/), which permits unrestricted use, distribution, and reproduction in any medium, provided you give appropriate credit to the original author(s) and the source, provide a link to the Creative Commons license, and indicate if changes were made. @- Cite as: Kaya. IZA Journal of Development and Migration (2021) 12:14 


\section{Introduction}

The literature on the gender wage gap (GWG) is long-established (see Blau and Kahn, 2017 for a recent review). Although the size of the gap varies considerably across countries and over time, a consistent finding in the literature is a persistent gender-based differential in pay in favor of men. While most of this evidence focuses on the mean of the wage distribution, an emerging body of evidence suggests that GWGs vary across the wage distribution (e.g., Albrecht et al., 2003; Arulampalam et al., 2007; De la Rica et al., 2008).

We add to this strand of the literature by exploring the GWG across the wage distribution in Turkey as an emerging economy. Using a linked employer-employee dataset, the Turkish Structure of Earnings Survey (SES) for 2006 and 2014, we separate the GWG across the wage distribution into its components: one part that can be explained by the differences in the observed productivity-related characteristics of men and women and another part that is due to gender differences in the returns to those characteristics that thus remain unexplained. By examining the GWG and its components across the distribution, we identify where the gap is most pronounced, for example, among low-paid or high-paid workers, defined as "sticky floor" and "glass ceiling" effects, respectively, in the context of the GWG (Albrecht et al., 2003; Arulampalam et al., 2007; De la Rica et al., 2008). The linked employer-employee nature of the SES data allows us to shed light on the two mechanisms that could give rise to economy-wide glass ceilings or sticky floors: one that operates between firms and another that operates within firms. The former relates to the fact that males and females are unevenly distributed across establishments and that low-paying establishments hire disproportionately more women than men, while the latter stems from gender wage disparities within firms (e.g., Javdani, 2015; Cardoso et al., 2016; Hara, 2018).

Our results show that the GWG in Turkey among comparable men and women is much wider within establishments than between establishments, so the extent of the influence of gender sorting across firms in explaining the GWG is limited. In fact, the largest portion of the economy-wide GWG arises from wage differentials that exist within establishments among otherwise comparable workers, which brings into question whether women and men are equally rewarded by employers. Our distributional analysis shows a more pronounced GWG among highly paid workers in Turkey, consistent with the presence of a glass-ceiling effect. This effect, however, is more apparent within establishments than between establishments, and it is the former that drives the economy-wide glass ceiling that women face, highlighting the importance of within-firm gender wage inequality.

Turkey forms an interesting case since during the past two decades, it has experienced a series of structural changes, including several policies enacted by the Turkish government that have increased the cost of hiring female employees (see Section 2). On one hand, this policy-driven change in the hiring costs of women may move females out of low-productive and low-paying firms. On the other hand, it may widen the GWG by depressing female wages within each firm as a result of rising costs. Although we do not test this directly, our analysis shows that between 2006 and 2014, the GWG in Turkey widened at all points of the wage distribution and that this widening was more pronounced within establishments than between establishments, providing evidence for the argument that the policy-driven change in the hiring costs of women may have increased the GWG. 


\section{Background}

\subsection{Related literature}

GWG is one of the most salient issues that has been investigated extensively in the literature (see Blau and Kahn, 2017 for a recent review). Most research has focused on the mean of the wage distribution and used the conventional Blinder-Oaxaca (BO) decomposition method (Blinder, 1973; Oaxaca, 1973) to separate the raw GWG into one part that can be explained by the gender differences in observable characteristics and another part that is due to gender differences in returns to those characteristics. Recent studies on European economies, however, have suggested that the GWG is not constant across the wage distribution even after controlling for observable personal, work-related, and firm characteristics, so comparing the average man and woman provides an incomplete picture (see Albrecht et al., 2003 for Sweden; Arulampalam et al., 2007 for a comparison of 11 European countries and De la Rica et al., 2008 for Spain). Using an extension of the $\mathrm{BO}$ decomposition to the (conditional) quantile regression models, these studies have shown that the GWGs in several countries are larger at the upper end of the wage distribution, consistent with the presence of glass-ceiling effects. ${ }^{1}$ We add to this strand of the empirical literature by exploring the GWG across the (unconditional) wage distribution in Turkey. ${ }^{2}$ Improving knowledge on whether GWG patterns are similar in emerging economies such as Turkey remains a particularly important issue, as women's relative positions in the labor market as well as government policies and labor market institutions differ significantly from European countries (see Section 2.2).

This paper is also related to the empirical literature on how within- and betweenestablishment effects are reflected in the GWG. The seminal studies in this field have emphasized the role of female segregation into lower-paying industries, occupations, establishments, and jobs within establishments (e.g., Sorensen, 1990; Groshen, 1991; Reilly and Wirjanto, 1999). However, the majority of this evidence is based on samples that are limited to a narrow range of occupations, industries, and regions. With the availability of large-scale linked employer-employee datasets, recent studies have explored the role of firms using nationally representative samples and by distinguishing the two dimensions: mechanisms that operate within- and between-firms (e.g., Bayard et al., 2003; Card et al., 2016; Jewell et al., 2020). These studies have consistently found that although the latter accounts for some fraction of the mean GWG, a sizeable portion of the GWG still persists from within-firm gender pay inequalities. Most of these studies, however, considered only the mean GWG, neglecting important insights offered by the wage distribution. The notable exceptions include Javdani (2015) and Cardoso et al. (2016), who found evidence of economy-wide glass-ceiling effects in Canada and Portugal, respectively, and Hara (2018), who found a larger GWG at the top and bottom ends of the wage distribution than in the middle, consistent with the presence of both glass ceiling and sticky

1 Existing theories on human capital, discrimination, and labor-market segmentation, however, fail to adequately explain a widening GWG at high pay levels (Peetz and Murray, 2017). Although glass-ceiling phenomena are rarely theorized, Peetz and Murray (2017) argue that the interaction between labor-market segmentation and the concept of regulation distance, that is, a greater role for less transparent, more subjective wage-setting arrangements for highly paid workers, helps understand a widening GWG at the upper end of the wage distribution.

2 In our analysis, we employ the unconditional quantile regression approach by Firpo et al. (2009). In contrast to the decomposition methods that are based on traditional conditional quantile regression, in this approach, the model is not sensitive to the covariates and the estimated coefficients can be interpreted as the impact of changes in the distribution of covariates on the quantiles of the unconditional marginal distribution of the dependent variable. We, nevertheless, explore the sensitivity of our results to the alternative decomposition methods (see Section 4). 
floor effects in Japan. Javdani (2015) and Cardoso et al. (2016) showed that economy-wide glass-ceiling effects faced by women are mainly due to mechanisms that operate between firms rather than within firms, while Hara (2018) found that the economy-wide glass-ceiling and sticky-floor effects in Japan were mainly driven by mechanisms that operate within firms rather than between firms. Evidence from these studies indicates that the role of within- and between-establishment effects on GWG is country-specific and it is of substantial interest to learn about the patterns in other countries, including Turkey.

During the past two decades, Turkey has experienced a series of structural changes that have increased the relative labor cost of female employees (see Section 2.2). The change in the overall GWG driven by changing labor costs is theoretically ambiguous and becomes an empirical question, with implications relevant not only to Turkey but also to other countries that have similar policies in place. Most empirical studies on the GWG in Turkey, however, have been carried out using data from the early 2000s or before (e.g., Tansel, 2005; Ilkkaracan and Selim, 2007), and the gap in post-structural change is relatively poorly studied. The only exception is Akhmedjonov (2012), who applied BO decomposition to data from the Turkish Household Budget Survey for 2009 and found that $>85 \%$ of the GWG in annual pay remains unexplained even after controlling for a wide range of characteristics. However, his analysis is limited to the mean and abstracts from firm effects and gender differences in work hours, both of which are important determinants of the GWG (Blau and Kahn, 2017).

\subsection{The Turkish context}

Turkey became an official candidate for the European Union (EU) in 1999 and began the accession negotiations in 2005. As a part of this process, Turkey has adapted its legislation to EU standards, including the EU Directives on gender equality policies. The constitutional amendments of 2001 and 2004, the adoption of the new Civil Code (2001), the new Labor Law (2003), and the new Penal Code (2005) are products of this process (Dedeoglu, 2012; 2013) (see Table B1 in Appendix B for a brief description of these policy changes). Despite the legal basis of gender equality in the workplace, the female labor force participation in Turkey is the lowest among the Organization for Economic Cooperation and Development (OECD) countries. In 2017 , only $37.6 \%$ of women were in the labor market, which was significantly behind the OECD average of $64 \%$ and the EU's Lisbon goals of $60 \%$, while the male labor force participation rate (78.2\%) was comparable to the OECD average of 80.2\% (OECD, 2017).

Several authors have argued that low female labor force participation in Turkey is, at least to some extent, due to cultural and social norms, which reinforce the position of women as wives and mothers (Dayioglu and Kirdar, 2010; Ilkkaracan, 2012). Despite improvements in the legal framework, the protective approach of the current labor regulation reinforces these traditional gender roles (Bugra, 2012) and makes it more constrained and more expensive for employers to hire women (World Bank, 2009; Anderson, 2017). For instance, until recently, the Labour Law prohibited women from doing night-time work. The 2003 amendments lifted this ban but kept some others, such as prohibiting the employment of women (and young men) in mines and underground or underwater activities, such as cabling, canalization, and tunnel construction. The current Labor Law also grants women the right to terminate employment contracts within a year of marriage and acquire severance payments based on 
this reason, whereas men are not entitled to severance pay in the case of marriage; as such, the law encourages women to focus on their roles as wives rather than on their labor market careers (Dedeoglu, 2012).

The prime change in the Labor Law, the extension of maternity leave from 12 weeks to a compulsory 16 weeks (plus an additional 6 months of unpaid leave) is also longer than the 14-week leave period in the EU and is not transferrable to the spouse. Although the generous maternity leave in Turkey may encourage women to maintain their labor market attachments, the lack of provision of paternity leave reinforces women's role as mothers (Dayioglu and Kirdar, 2010; Ilkkaracan, 2012) and may discourage employers from hiring women (World Bank, 2006). Another primary change in the new Labor Law is the requirement for any workplace with 100-150 female employees to set up a nursing room that is separate from the workplace but within a distance of $250 \mathrm{~m}$ and for any workplace with at least 150 female workers to provide a childcare center for children below six and a separate facility or nursery close to the workplace for breastfeeding mothers. The dependence of childcare provision on the number of female workers not only implies childcare as a woman's responsibility but also increases the cost of female workers relative to male workers (Dayioglu and Kirdar, 2010) and may become an indirect form of discrimination against women, as the employers must bear this cost (Anker, 1997).

In terms of the institutional setting, Turkey has a statutory national minimum wage set by the government after nonbinding tripartite consultations, and the Minimum Wage Regulation (Law Number 25540) states that "no gender difference can be considered in setting minimum wage". However, the minimum wage is binding for the formal sector and for low-skilled women in particular (World Bank, 2009). Thus, the increase in the minimum wage between 2005 and 2015 (approximately 10\% each year on average, corresponding to a cumulative real increase of $24 \%$ ) increased the cost of low-skilled workers in the formal sector, many of whom are youth and women, lowering the demand for this group and pushing them into the informal economy (World Bank, 2009). Indeed, despite the dramatic increase in the minimum wage in Turkey in the 2000s, the current minimum monthly gross wage is 2,943 Turkish Lira (TRY) (around 279.35 pounds), ranking the country among the lowest in Europe.

The 2008 Employment Package, on the other hand, introduced reforms that were designed to increase the formal labor demand for individuals in these groups by reducing their employment costs in the form of subsidizing employer social security contributions for newly hired youth and female workers in the first year, with reduced rates over a 5-year period. However, the evidence suggests that this reform did not have an overall statistically significant effect on women's formal employment in Turkey (Balkan et al., 2016), possibly due to low levels of labor demand as a result of the economic crisis during the period of implementation (World Bank, 2009). The labor market effects of the global economic crisis are also worth noting. Although, evidence suggests that Turkey recovered fast from the global financial crisis, the labor market effects of the crisis were not gender neutral (see Yucel, 2015 for a similar discussion). In particular, women's employment in Turkey increased substantially at the initial stages of the crisis, confirming a case for the added worker hypothesis that suggests women who did not previously participate in the labor market may enter into the labor force to compensate for the job loss of their husbands. Such increase in women's labor market participation, may lead to differential changes in selection patterns for men and women (see Dolado et al. 2020 for 
evidence from European countries). Indeed, it is widely recognized that non-random selection into employment may also create a negative correlation between female labor force participation and the GWG (Olivetti and Petrongolo, 2008). Once that is taken into account, in countries with high employment gaps, the GWG is usually larger, consistent with the positive selection into employment for women. ${ }^{3}$

\section{Data}

\subsection{The SES}

The data used in this study come from the Turkish linked employer-employee SES dataset for 2006 and 2014. SES is carried out by the Turkish Statistical Institute, the official government agency commissioned with producing official statistics for Turkey, at 4 yearly intervals from 2006 until 2014. The main aim of the survey is to give detailed information on earnings from and hours of formal employment. As such, the SES includes detailed information provided by employers on the contractual weekly working hours, monthly paid hours, monthly average basic and gross pay, and information on the key characteristics of workers and their jobs and employers.

The SES adopts a two-stage stratified random sampling method. In the first stage, local units associated with firms with 10 or more employees are selected, and in the second stage, employees from the selected local units are sampled. Establishments with at least 10 employees in all sectors of the formal economy, except agriculture, public administration and defense, and compulsory social security, are covered by the survey, which forms about $70 \%$ of the paid employment in the formal sector in Turkey (see Appendix A).

The SES dataset has clear advantages over surveys based on household data, as the information on hours and earnings are based on employer records considered the most reliable (Cebeci, 2015). Moreover, as it is a linked employer-employee dataset, it enables comparisons between the hourly wages of men and women working at the same establishment through within-establishment analysis. ${ }^{4}$ Its main limitation is, owing to its cross-sectional nature, we cannot control for worker fixed effects that could account for unobserved worker heterogeneity, such as differences in productivity and preferences. Another limitation is that the SES does not include information on the family structure or household composition of employees nor information on the number of female workers within establishments. The size of the firm to which the establishment belongs is available (in terms of the number of employees), but the categorical nature of this variable prevents us from using it to approximate the exact number of female employees within establishments. ${ }^{5}$ Therefore, we cannot directly test the impact

3 Given the low female labor force participation in Turkey, the non-random selection into employment is a concern. Unfortunately, SES does not provide information on the household context (e.g. marital status or children) or information on non-participations to account for non-random selection into employment using the conventional twostage Heckman (1979) approach. However, we explore the sensitivity of our main results to the potential heterogeneity in the sample data using a matching estimate as an alternative to the BO decomposition (see Section 4).

4 It is worth noting that the survey unit in the SES is the establishment, not the firm to which the establishment belongs. Hence, in our analysis, we control for establishment fixed effects rather than firm fixed effects. However, as all establishments within a firm adhere to the same rules determined at the firm level, controlling for establishment fixed effects is essentially the same as controlling for firm fixed effects (see Hara, 2018 for a similar approach).

5 SES data include information on the gender of the employee and an establishment identifier, which enable to calculate the average share of females within the workplace. However, in the absence of exact firm size, this does not allow us to calculate the exact number of female employees within each establishment. 
of the recent structural changes that increased the relative labor costs of female workers (see above discussion). Nevertheless, in our analysis, we use the first and last available editions of the SES data for 2006 and 2014 and explore the changes in the GWG and its drivers over time. ${ }^{6}$ Although we do not infer a causal relationship, this analysis is informative about the relationship between the recent structural changes affecting labor costs and the GWG. Finally, due to coverage by the SES, all the findings in this study are related only to formal employment in firms with 10 or more workers in the covered areas of economic activity.

Our dependent variable is (log) hourly wage, which is calculated as the simple division of monthly gross pay by monthly paid hours and deflated using the Consumer Price Index base year 2003. In our analyses, we control for personal characteristics, such as educational attainment and years of potential experience (and squared), and work-related characteristics, including years of tenure with current employer (and tenure squared), full-time employment (a binary indicator that takes a value of 1 if the job is full-time and 0 otherwise), permanent employment contract (a binary indicator that takes a value of 1 if the job is temporary and 0 otherwise), and overtime work (a binary indicator that takes a value of 1 if the employee worked overtime and 0 otherwise). We also have information on employees' occupations; however, as occupation and wages are likely to be jointly determined, our benchmark estimates do not include occupation (see Albrecht et al., 2003 for a similar discussion). Nonetheless, we explore the sensitivity of our results to the inclusion of occupation dummies (see Section 4).

In terms of employer characteristics, SES includes the size band of the firm to which an establishment belongs (in terms of the number of employees), collective bargaining (a binary indicator that takes a value of 1 if a collective pay agreement exists in the establishment and 0 otherwise) and the industry of the establishment. Although no information exists on other employer characteristics that have been found to be important in the literature, such as the public/private sector (e.g., Chatterji et al., 2011) or type of ownership (e.g., Magda and Salach, 2019), this is less of a concern here, as SES data allow us to control for establishment fixed effects, which account for both observed characteristics (including firm size, industry, and collective agreement) and unobserved characteristics (such as market power and managerial ability) that are shared by all the workers employed at the same establishment. The region, another important variable in explaining the GWG (e.g., Hirsch et al., 2013), is available for 2014 but not for 2006. For comparative purposes, in our benchmark analysis, we do not include a control for region, but we also test the sensitivity of our results for 2014 to the inclusion of region (see Section 4). Table A1 in Appendix A provides a detailed description of all the variables and their construction.

\subsection{Sample statistics}

In our analysis, we restrict our sample to individuals of working age (those aged 15-64) excluding paid stagers and apprentices. ${ }^{7}$ To examine the extent to which the GWG derives from within-establishment mechanisms, we further restrict our sample to employees at establishments

6 SES data for 2010 are also available, but we do not use this information to avoid the altering the short-term (gendered) effects of the global economic crisis (see above discussion).

7 Our age restriction is consistent with the OECD (2021) definition of working age, but our findings are robust to excluding the youngest cohorts from our sample (see Section 4). 
that employ both males and females and ensure that there are at least two observations per establishment. Our final samples include 241,361 observations from 12,874 establishments in 2006 and 132,235 observations from 7,867 establishments in 2014.

In Table B2 in Appendix B, we present the sample means for establishments to illustrate how establishment characteristics in our sample have changed over time. These statistics show that compared with 2006, there were fewer but larger firms in 2014 with an increased fraction of establishments engaged in collective bargaining. The change in the firm-size composition of our sample is consistent with the findings of Atiyas et al. (2017), who studied the changes in firm and employment dynamics in Turkey between 2005 and 2014 and found that the distribution of employment moved from small firms to larger firms. Additionally, we observe changes in the industry composition of establishments from 2006 to 2014, with a relative shift from manufacturing to wholesale and retail trade, a trend that has been observed in Turkey since the 1980s and is shared by other emerging economies (Gezici et al., 2017).

In Tables B3 and B4 in Appendix B, we also present the sample means of explanatory variables for employees within and across all establishments. These conform to some wellestablished gender differences and display largely common patterns in both years. However, they also highlight important features of the Turkish labor market. Consistent with the increase in the female employment rates in Turkey over recent decades (OECD, 2019), from 2006 to 2014, there was an increase in the fraction of females within establishments. Female employees in our sample are increasingly more highly qualified than males, a feature commonly observed in other emerging economies (OECD, 2017). However, they have shorter average potential experience and firm tenure than males. Over time, there has been a decline in the average tenure of both males and females, consistent with the increase in the retail industry (see Table B2 in Appendix B), where average tenures are typically shorter (Auer and Cazes, 2000). Nonetheless, both within and across establishments, the gender differences in experience and tenure have narrowed over time. Confirming the well-established gender differences in overtime work, female employees worked relatively less overtime in both years, and they were also less likely to be covered by a collective pay agreement than men. However, there is no significant gender difference in firm size, full-time or permanent employment in our samples.

Turning our attention to our dependent variable, Figure 1 presents the kernel estimates of the wage densities for men and women in 2006 and 2014. By contrasting the male and female kernel density estimates in each year, we obtain a visual inspection of the GWG. In Figure 1, the distributions are hardly distinguishable in 2006, suggesting a closed GWG, particularly at the bottom and in the middle of the wage distribution. From 2006 to 2014, the average hourly real wage in our sample increased for both males (by 20\%) and females (by 12\%), and as a result, the male and female wage distributions shifted to the right. However, the unequal growth in the wages of men and women led to an increased average GWG, which may be attributed to increases in the gap throughout the wage distribution. In fact, this becomes apparent in Figure 2, where we present the observed GWG for each year, calculated as the difference in the (log) hourly wages of men and women at each percentile of the wage distribution. In 2006, there is a closed GWG at the bottom of the wage distribution, but the gap widens as we move up the wage distribution and then declines at the top. In 2014, however, there is an apparent 
Figure 1 Kernel density estimates of the wage distributions, by year and sex.

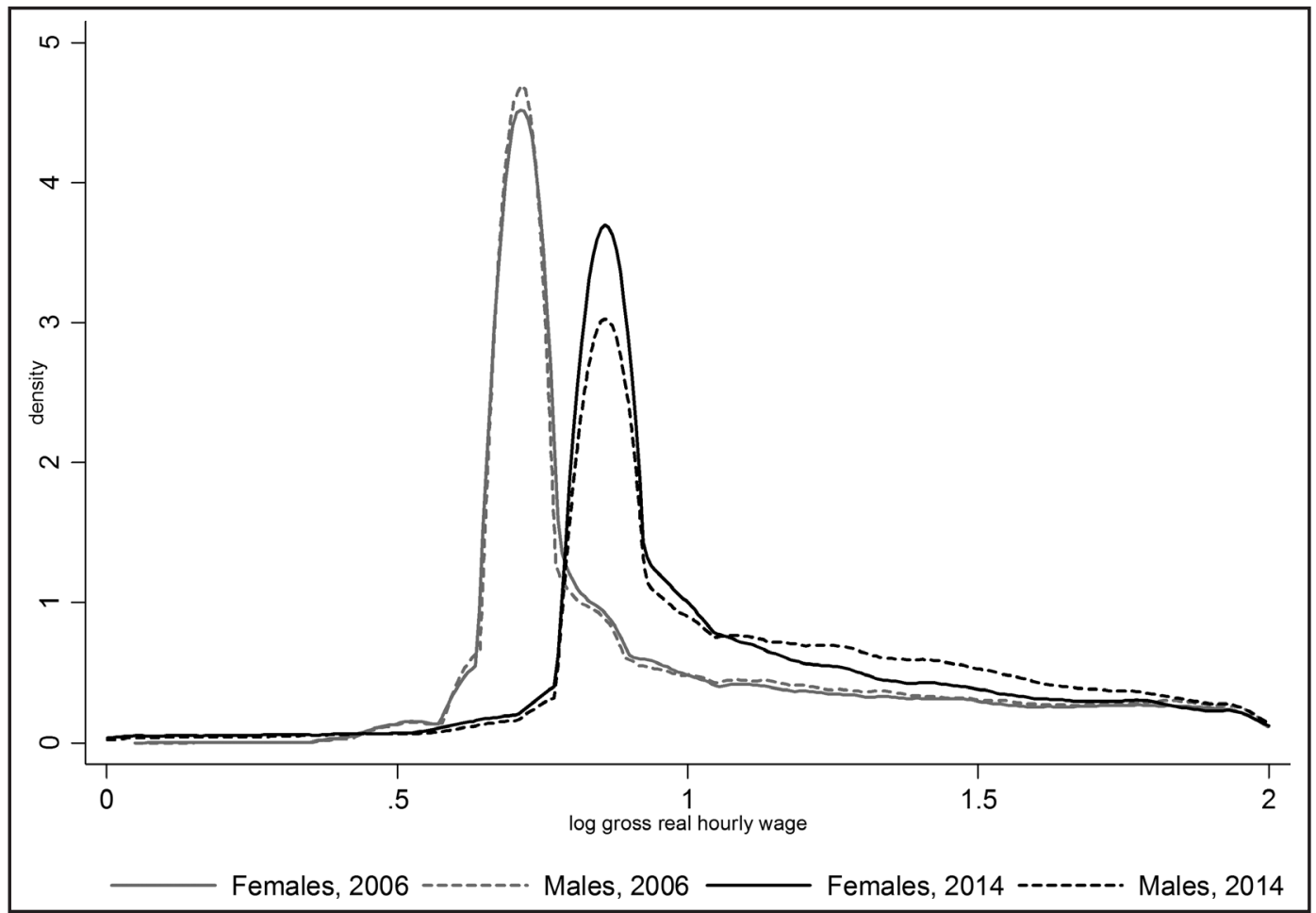

Data source: Author's calculations based on the SES 2006 and 2014.

Notes: The density functions are estimated using the Epanechnikov Kernel estimator. SES, Structure of Earnings Survey.

Figure 2 Observed GWG, 2006 and 2014.

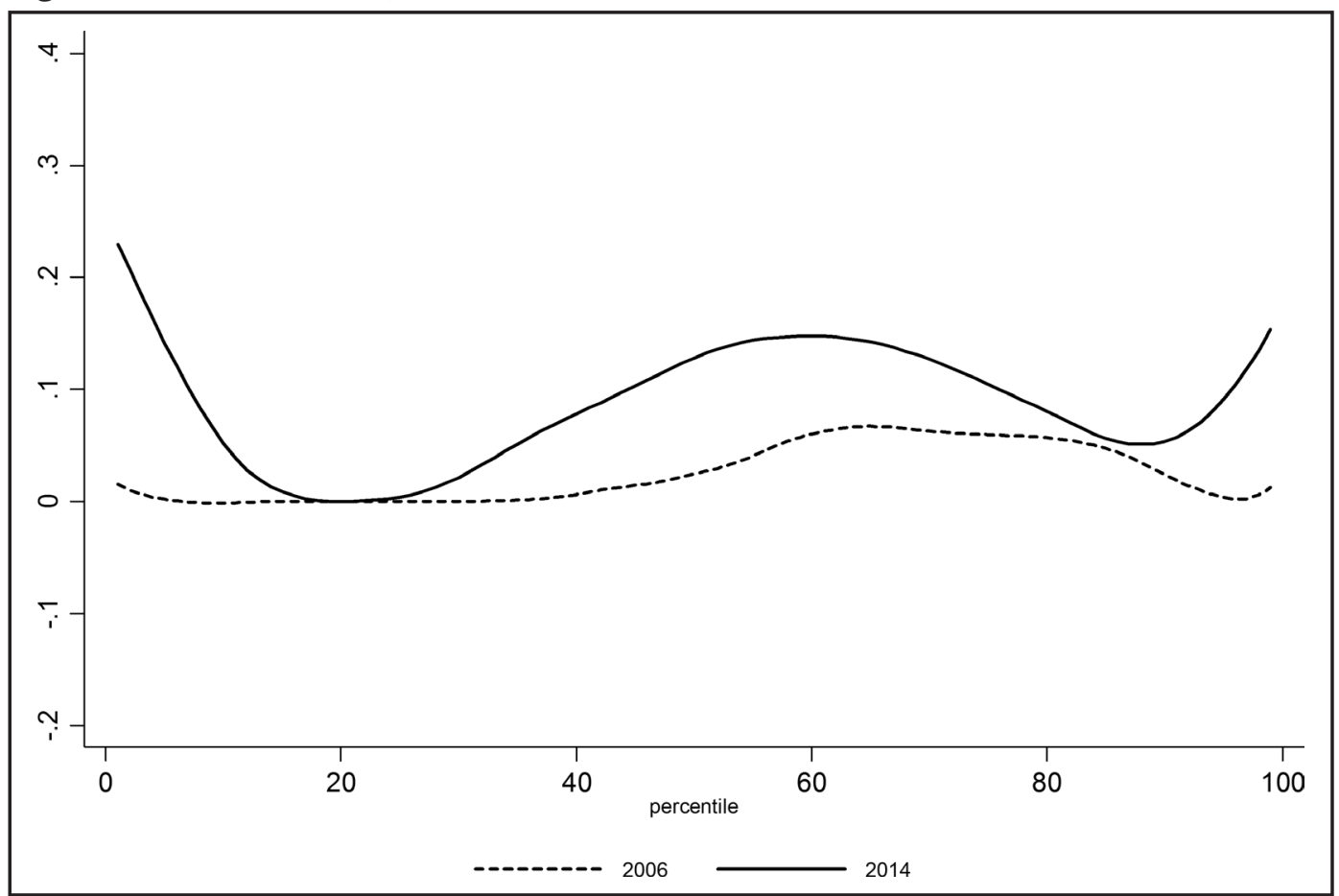

Data source: Author's calculations based on the SES 2006 and 2014.

Notes: The observed GWG is the difference between the log hourly wages of men and women. The graph is created using lowess smoothing, with a bandwidth of 0.25. GWG, gender wage gap; SES, Structure of Earnings Survey. 
W-shape distribution, with wider GWGs at the two ends of the wage distribution and in the middle. Moreover, the GWG in 2014 is wider than in 2006 at all points in the wage distribution except between the 13th and 26th percentiles, where there is no observed GWG. In the next section, we explore these descriptive patterns in more detail and provide evidence for their potential drivers.

\section{Econometric results}

\subsection{The GWG at the mean}

To estimate the economy-wide GWG across all establishments, we use a simple ordinary least squares (OLS) wage equation that pools observations from both male and female workers in each year as:

$$
\ln w_{i j}=\alpha g_{i j}+\boldsymbol{x}_{i j} \boldsymbol{\beta}+u_{i j} .
$$

where $\ln w_{i j}$ is the log hourly wage of individual $i$ (for $i=1, \ldots, \mathrm{N}$ ) working in establishment $j$ (for $j=1, \ldots, \mathrm{M}), g_{i j}$ is the binary indicator of gender (for males $g=m$ and for females $g=f$ ) and $\boldsymbol{x}_{i j}$ is a vector of explanatory variables. In the first specification (Specification (1)), we regress the log hourly wage on a binary indicator of gender that takes a value of 1 for males and 0 for females and a constant term. The coefficient estimate of the male dummy in this specification provides a measure of the economy-wide raw GWG that does not consider any gender differences in terms of productivity-related characteristics. We then estimate four more specifications where we gradually add the personal characteristics (Specification (2a)), work-related characteristics (Specification (2b)), and observed firm and establishments characteristics (Specification (2c)) discussed above. The estimate of the male dummy coefficient estimate from each of these specifications provides information on the mean GWG adjusted for the covariates included in the model. In our final specification (Specification (2d)), in addition to personal and workrelated characteristics, we control for establishment fixed effects, which account for observed (such as industry, firm size, and collective pay agreement) and unobserved (such as managerial ability and market power) firm characteristics that are shared by all the workers employed at the same establishment. Formally, to estimate the within-establishment GWG, we consider a version of Eq. (1):

$$
\ln w_{i j}=\alpha g_{i j}+\boldsymbol{x}_{i j} \boldsymbol{\beta}+f_{j}+u_{i j}
$$

where $f_{j}$ is the full set of establishment dummies (for $j=1, \ldots, \mathrm{M}$ ), i.e., establishment fixed effects. ${ }^{8}$ As the fixed-effects approach exploits variation within establishments, this enables us to compare men and women with the same characteristics working in the same establishment. In other words, the male dummy coefficient estimate in this specification (Specification (2d)) provides information on within-establishment adjusted GWG. As the economy-wide GWG that exists among comparable men and women might stem from two

8 As proposed by Mundlak (1978), analytically equivalent estimates of $\boldsymbol{\beta}$ can be obtained using the following model: $\ln w_{i j}=\alpha g_{i j}+\boldsymbol{x}_{i j} \boldsymbol{\beta}+\overline{\boldsymbol{x}}_{\boldsymbol{j}} \boldsymbol{\gamma}+u_{i j}$ where $\overline{\boldsymbol{x}}_{\boldsymbol{j}}$ are establishment-level averages of the covariates - so called Mundlak terms. Our benchmark estimates are based on equation (2), but we use Mundlak terms when we explore sensitivity of our results to using (conditional) quantile regressions which are computationally demanding to estimate with a large set of fixed effects. 
different mechanisms, one that operates within firms and another between firms, the difference between the estimates from Specifications (2b) and (2d) is informative about the between-establishment GWG. ${ }^{9}$ While the GWG that females face within establishments would arise in the presence of within-firm pay inequalities, the between-establishment GWG would stem from the disproportionate sorting of men and women across low- and highpaying establishments (Javdani, 2015; Hara, 2018).

Table 1 presents these results, where we focus on our key variable and present the coefficient estimates on the male indicator. The full set of coefficient estimates on all other explanatory variables is available upon request, but they generally conform to expectations with higher returns to higher levels of education, a positive but diminishing return to experience and tenure, a permanent contract premium, a firm size premium, a premium attached to any collective bargaining agreement, and differential returns to different industries. However, in contrast to most developed countries (see Fernández-Kranz and Rodríguez-Planas, 2011 for Spain and Mumford and Smith, 2009 for Britain) but consistent with previous evidence for

Table 1 Raw and adjusted GWG at the mean

\begin{tabular}{|c|c|c|c|c|c|}
\hline \multirow[b]{2}{*}{ Specification } & \multirow{2}{*}{$\frac{\text { Raw GWG }}{(1)}$} & \multicolumn{4}{|c|}{ Adjusted GWG } \\
\hline & & (2a) & (2b) & (2c) & (2d) \\
\hline \multirow[t]{2}{*}{2006} & $0.024^{\star \star \star}$ & $0.051^{\star \star \star}$ & $0.048^{\star \star \star}$ & $0.048^{\star \star \star}$ & $0.051^{\star \star \star}$ \\
\hline & $(0.007)$ & $(0.005)$ & $(0.004)$ & $(0.004)$ & $(0.002)$ \\
\hline \multirow[t]{2}{*}{2014} & $0.084^{\star \star \star}$ & $0.122^{\star \star \star}$ & $0.108^{\star \star \star}$ & $0.106^{\star \star \star}$ & $0.095^{\star \star \star}$ \\
\hline & $(0.009)$ & $(0.007)$ & $(0.006)$ & $(0.006)$ & $(0.004)$ \\
\hline Personal characteristics & No & Yes & Yes & Yes & Yes \\
\hline Work-related characteristics & No & No & Yes & Yes & Yes \\
\hline $\begin{array}{l}\text { Observed firm and estab- } \\
\text { lishment characteristics }\end{array}$ & No & No & No & Yes & No \\
\hline Establishment fixed effects & No & No & No & No & Yes \\
\hline
\end{tabular}

Data source: Author's calculations based on the SES 2006 and 2014.

Notes: (i) Sample is restricted to individuals of working age (between 15 years old and 64 years old), excluding paid stagers and apprentices, who are employed in establishments that employ both males and females. The data are not weighted. (ii) The numbers in parentheses are establishment-level clustered standard errors. (iii) ${ }^{\star},{ }^{\star \star}$, and ${ }^{\star \star \star}$ denote significance at $0.001,0.01$, and 0.05 significance levels, respectively. (iv) Reported are male dummy coefficient estimates from various specifications. Each coefficient and associated standard error reported comes from a separate regression. Personal characteristics include educational attainment and potential experience (and experience squared). Work-related characteristics are tenure (and tenure squared), full-time employment, permanent employment contract, and an overtime work indicator. Observed firm characteristics include firm size, collective agreement coverage, and industry. All specifications include a constant term. See Table A1 in Appendix A for variables definitions. (v) Number of observations is $241,361(132,253)$ in 2006 (2014) in all regressions.

GWG, gender wage gap; SES, Structure of Earnings Survey.

9 In this comparison, we use estimates from Specification (2b) instead of Specification (2c). As in the case of withinestablishment analysis, firm-fixed effects would absorb the effect of industry, firm size, and collective pay agreement, therefore, their inclusion in Specification (2d) would not be feasible. For comparative purposes, the adjusted GWG across all establishments from Specification (2b) excludes these characteristics. 
Turkey (see Aldan and Yunculer, 2017), we find a significant part-time premium. Overtime work is also associated with a premium, although this turns out to be either insignificant or negative once we account for firm heterogeneity. This might reflect the fact that, in contrast to many European countries, in Turkey, low-skilled workers are more likely to work overtime (Anxo and Karlsson, 2019).

Turning our attention to the results presented in Table 1, the estimates from Specification (1) suggest a significant raw GWG in each year, but the gap increased from 0.024 log points (2.4\%) in 2006 to $0.084 \log$ points $(8.8 \%)$ in 2014 . When personal characteristics are controlled for (Specification (2a)), the GWG widens substantially in both years. This contrasts starkly with the evidence from European countries but is consistent with the descriptive statistics presented above, indicating that women are more highly qualified than men on average, particularly in terms of education. While the inclusion of work-related characteristics narrows the GWG slightly in each year (Specification (2b)), observed firm and establishment characteristics appear to have a limited influence (Specification (2c)). The coefficient estimates from Specification (2d), where we control for establishment fixed-effects, however, reveal a substantial within-establishment GWG (about 0.051 log points in 2006 and 0.095 log points in 2014), bringing into question whether women and men in Turkey are equally rewarded by employers.

A comparison of estimates from Specifications (2b) and (2d) suggests that the within-establishment GWG between comparable men and women is the main driver of the economy-wide adjusted GWG. For instance, the within-establishment adjusted GWG (Specification (2d)) is similar in magnitude to the economy-wide adjusted GWG (Specification (2b)), while in 2014 , it forms $>87 \%$ of the economy-wide gap. As discussed in Section 2.2, from 2006 to 2014, Turkey experienced a series of changes that increased the relative cost of female employees. On one hand, this change could move females out of low-productive, low-paying firms. On the other hand, it may increase the within-establishment GWG by depressing female wages within each firm. Consistent with the latter, our results indicate a $4.4(\mathrm{log})$ percentage point increase in within-establishment adjusted GWG from 2006 to 2014 (from $0.051 \log$ points to $0.095 \log$ points). This is smaller than the $6(\log )$ percentage point increase in the economy-wide adjusted GWG (from 0.048 log points to $0.108 \log$ points), also suggesting a widening between-establishment adjusted GWG. The increase in between-establishment adjusted GWG, however, contributes a modest proportion (less than one-third) to the $6(\log )$ percentage point rise in the economy-wide GWG, implying that increasing pay inequalities within establishments were the main drivers of the widening of the GWG.

\subsection{Decomposition of the mean GWG}

The results presented in Table 1 are based on wage equations that assume that returns to characteristics are the same for men and women. To examine the extent to which the returns to characteristics differ by gender, a version of wage Eq. (3) can be estimated separately for males and females as follows:

$$
\ln w_{i j, g}=\boldsymbol{x}_{i j, g} \beta_{g}+u_{i j, g} .
$$


The OLS estimates of the gender specific coefficient vectors $\hat{\boldsymbol{\beta}}_{\boldsymbol{g}}$ (for males $g=m$ and for females $g=f$ ) from Eq. (3) can be then used in BO decomposition which has been widely used to analyze the GWG. Consistent with the literature (see Blau and Kahn, 2017 for a recent review), we decompose the raw GWG into its explained and unexplained components (Blinder, 1973; Oaxaca, 1973) as follows:

$$
\overline{\ln w}_{m}-\overline{\ln w}_{f}=\underbrace{\left(\overline{\boldsymbol{x}}_{m}-\overline{\boldsymbol{x}}_{f}\right) \hat{\boldsymbol{\beta}}_{\boldsymbol{m}}}_{\text {explained gap }}+\underbrace{\overline{\boldsymbol{x}}_{f}\left(\hat{\boldsymbol{\beta}}_{\boldsymbol{m}}-\hat{\boldsymbol{\beta}}_{f}\right)}_{\text {unexplained gap }}
$$

where the bar above a variable denotes the mean value. ${ }^{10,11}$ In Eq. (4), the first component, named the explained gap, measures the part of the GWG that is due to gender differences in the observed characteristics, while the second component is the part that is due to gender differences in the returns to those characteristics and thus remains unexplained.

In Table 2, we present the $\mathrm{BO}$ decomposition results performed by estimating Specifications (2a)-(2d) separately for males and females for each year. ${ }^{12}$ Within each panel, the difference in log hourly wages between the average male and female is presented in the first row ("Raw GWG"), and "explained" and "unexplained" gaps are the two components of the GWG obtained from the BO decomposition. ${ }^{13}$ In contrast with evidence from developed countries but consistent with the findings from the pooled model, the explained component of the GWG is negative and statistically significant in all columns within each panel. This suggests that, on average, women in Turkey have superior productivity-related characteristics than men, such as higher educational attainment. In Specification (2a), the explained gap is of similar absolute magnitude to the raw GWG in 2006, leaving an unexplained gap nearly double the raw GWG, while the unexplained gap in 2014 is about one and half times the raw GWG. While including work-related characteristics (Specification (2b)) and observed firm and establishment characteristics (Specification (2c)) slightly narrows the unexplained gap in 2014 , they appear to have a limited influence in 2006. Once establishment fixed effects are controlled for (Specification (2d)), the unexplained gap narrows slightly in both years. This suggests that the GWG, was partly due to mechanisms operating between firms. Nevertheless, the within-establishment unexplained gap accounts for much of the economy-wide unexplained gap in both years. For instance, a comparison of the unexplained gaps from Specifications (2b)

10 To identify the contribution of each covariate to the explained component, we apply the normalized regression method proposed by Suits (1984) and Yun (2005), which transforms the coefficients vectors of the categorical variables so that the results of the $\mathrm{BO}$ decomposition are independent of the choice of the omitted category.

11 Following the earlier literature (see Blau and Kahn, 2017), Eq. (4) uses as the counterfactual the (log) hourly wage of an average woman at the male returns under the assumption that the returns derived from the male wage regression are equivalent to competitive prices. However, the change in reference coefficients makes little difference to our estimates (see Appendix Table B5).

12 A full set of coefficient estimates is available upon request, but they show lower returns to higher education levels for women and a higher firm-size wage premium for men in both years. Although we find a higher return to experience for women in 2006, in 2014 this is reversed with men receiving a higher return to experience. We also find that males receive a higher return to tenure and have a pay advantage for working in establishments with collective agreement bargaining coverage in 2006, but these turn to a female advantage in 2014.

13 In Tables B6 and B7 in Appendix B, we present the detailed decomposition of the explained gap, where the contribution of each covariate is identified. Consistent with women having higher qualifications than men, gender differences in education make the largest (negative) contribution and narrow the GWG in both years, while gender differences in experience and tenure, the other two largest contributors, work to widen the GWG and partly offset this effect. It is also worth noting that in Specification (2d), gender differences in the constant terms are informative about the gender difference in the average establishment fixed effects. Although these appear not to have a statistically significant influence on the GWG at the mean, our further analyses reveal that these effects are not constant across the distribution but without a clear pattern (results available upon request). 
Table 2 Decomposition of the GWG at the mean

\begin{tabular}{|c|c|c|c|c|}
\hline & \multicolumn{4}{|c|}{ Specification } \\
\hline & (2a) & (2b) & (2c) & $(2 d)$ \\
\hline \multicolumn{5}{|l|}{2006} \\
\hline \multirow[t]{2}{*}{ Raw GWG } & $0.024^{\star \star \star}$ & $0.024^{\star \star \star}$ & $0.024^{\star \star \star}$ & $0.024^{\star \star \star}$ \\
\hline & $(0.006)$ & $(0.006)$ & $(0.006)$ & $(0.006)$ \\
\hline \multirow[t]{3}{*}{ Explained gap } & $-0.023^{\star \star \star}$ & $-0.025^{\star \star \star}$ & $-0.024^{\star \star \star}$ & $-0.016^{\star \star \star}$ \\
\hline & $(0.004)$ & $(0.004)$ & $(0.005)$ & $(0.001)$ \\
\hline & {$[-97.2 \%]$} & {$[-104.8 \%]$} & {$[-103.1 \%]$} & {$[-65.9 \%]$} \\
\hline \multirow[t]{3}{*}{ Unexplained gap } & $0.047^{\star \star \star}$ & $0.049^{\star \star \star}$ & $0.048^{\star \star \star}$ & $0.039^{\star \star \star}$ \\
\hline & $(0.005)$ & $(0.004)$ & $(0.004)$ & $(0.001)$ \\
\hline & {$[197.2 \%]$} & [204.8\%] & [203.1\%] & [165.9\%] \\
\hline \multicolumn{5}{|l|}{2014} \\
\hline \multirow[t]{2}{*}{ Raw GWG } & $0.084^{\star \star \star}$ & $0.084^{\star \star \star}$ & $0.084^{\star \star \star}$ & $0.084^{\star \star \star}$ \\
\hline & $(0.008)$ & $(0.008)$ & $(0.008)$ & $(0.008)$ \\
\hline \multirow[t]{3}{*}{ Explained gap } & $-0.035^{\star \star \star}$ & $-0.024^{\star \star \star}$ & $-0.019^{\star \star \star}$ & $-0.008^{\star \star *}$ \\
\hline & $(0.005)$ & $(0.005)$ & $(0.006)$ & $(0.002)$ \\
\hline & {$[-41.9 \%]$} & {$[-29.1 \%]$} & {$[-22.8 \%]$} & {$[-9.0 \%]$} \\
\hline \multirow[t]{3}{*}{ Unexplained gap } & $0.119^{\star \star \star}$ & $0.108^{\star \star \star}$ & $0.103^{\star \star \star}$ & $0.092^{\star \star \star}$ \\
\hline & $(0.007)$ & $(0.006)$ & $(0.006)$ & $(0.003)$ \\
\hline & [141.9\%] & [129.1\%] & [122.8\%] & [109.0\%] \\
\hline
\end{tabular}

Data source: Author's calculations based on the SES 2006 and 2014.

Notes: (i) Sample is restricted to individuals of working age (between 15 years old and 64 years old), excluding paid stagers and apprentices, who are employed in establishments that employ both males and females. The data are not weighted. (ii) Figures in () are establishment level clustered standard errors. (iii) * ${ }^{* \star}$, and ${ }^{\star \star *}$ denote significance at 0.001, 0.01, and 0.05 significance levels, respectively. (iv) BO method is used to decompose the mean GWG using relevant male coefficients as the baseline. (v) Specifications (2a)-(2d) are as set out in the text. (vi) Figures in [] are proportions of the raw GWG.

BO, Blinder-Oaxaca; GWG, gender wage gap; SES, Structure of Earnings Survey.

and $(2 \mathrm{~d})$ reveals that the within-establishment unexplained gap of 0.039 log points in 2006 is around $80 \%$ of the $0.049 \log$ points economy-wide unexplained gap. From 2006 to 2014, there is a $5.3(\mathrm{log})$ percentage point rise in the within-establishment unexplained gap (from 0.039 $\log$ points to $0.092 \log$ points), and this is around $90 \%$ of the $5.9(\log )$ percentage point increase in the economy-wide unexplained gap (from $0.049 \mathrm{log}$ points to $0.108 \mathrm{log}$ points). Consistent with the results from the pooled model, this confirms the role of within-establishment pay inequalities in driving the increasing wage differential between men and women in Turkey during this period.

Before we move to the distributional analysis, it is worth noting that a valid concern surrounding our empirical strategy is the non-randomness of selection into work particularly given the low female labor force participation rates in Turkey. If the selection process into work is not exactly the same for men and women, this could lead to biased estimates of the unexplained component of the GWG. In order to address the potential heterogeneity in the sample data, we follow Meara et al. (2020) and use the propensity score matching (PSM) 
method as an alternative to the BO decomposition. Further details are reported in Table B8 in Appendix B, but these analyses produce an estimate of a statistically significant average treatment effect on the treated (ATT) (GWG) of about 0.020 log points for 2006 sample and of about $0.065 \log$ points for the 2014 sample. Consistent with the presence of potential heterogeneity in the sample data and the findings of the previous literature (see Meara et al. 2020 for a discussion), these estimates are lower than the unexplained components obtained from the BO decomposition. Nevertheless, the main pattern remains consistent, with a widening of the GWG between the 2 years. In fact, the increase in the estimated gap between 2006 and 2014 from PSM is of comparable magnitude to the economy-wide increase in the unexplained GWG obtained from the BO decomposition (at around 4.5-6.3 (log) percentage points).

\subsection{The GWG across the distribution}

Next, we explore whether the GWG differs across the wage distribution and estimate the GWG at different points of the wage distribution using the unconditional quantile regression model proposed by Firpo et al. (2009) which is based on a recentered influence function (RIF). The method is similar to the standard OLS regression, except that the RIF of the statistic of interest is used as a dependent variable (Fortin et al., 2011). ${ }^{14}$ In the case of quantiles, the RIF of the $\tau$-th quantile of the unconditional distribution of dependent variable $Y$ (in our case (log) hourly wage) $Q_{\tau}$ is given as:

$$
R I F\left(Y, Q_{\tau}\right)=Q_{\tau}+\frac{\left(\tau-\mathbb{1}\left\{Y \leq Q_{\tau}\right\}\right)}{f_{Y}\left(Q_{\tau}\right)}
$$

where $\mathbb{1}\{\cdot\}$ is an indicator function for whether the observed $Y$ is at or below quantile $Q_{\tau}$ and $f_{Y}(\cdot)$ is the marginal density function of $Y$. The conditional expectation of $R I F\left(Y, Q_{\tau}\right)$ given covariates $X$ can then be modeled as a function of $X$, where the resulting coefficient estimates capture the marginal effect of a change in covariates on the unconditional quantile of the dependent variable (Firpo et al. 2009). In the simplest approach, $R I F\left(Y, Q_{\tau}\right)$ can be modeled as a linear function of covariates and estimated using the OLS (RIF-OLS).

Parallel to the analysis at the mean, Table 3 presents RIF-OLS regression estimates of the male dummy for selected percentiles of the wage distribution using the five specifications presented above. For comparison, estimates for the mean are displayed in the last column. A comparison of the male coefficient estimates within each row of Table 3 enables us to identify where the GWG is more pronounced. The previous literature (e.g., Albrecht et al., 2003; Arulampalam et al., 2007) has defined the existence of a glass-ceiling effect if the adjusted (or unexplained) GWG at the 90th percentile exceeds the gap at other reference points (e.g., the 50 th or 75 th percentiles) of the wage distribution by at least two percentage points. Similarly, the existence of a sticky-floor effect is determined if the adjusted GWG at the 10th percentile of the wage distribution exceeds the gap at the 25 th or 50 th percentiles. For instance, if females are under-represented at the top of the wage distribution and their under-representation

14 In Figures B1 and B2 in Appendix, we explore the sensitivity of our findings to the decomposition method, by using the Machado and Mata (2005) decomposition. While the precise point estimates vary, the patterns remain robust to the decomposition method employed. 


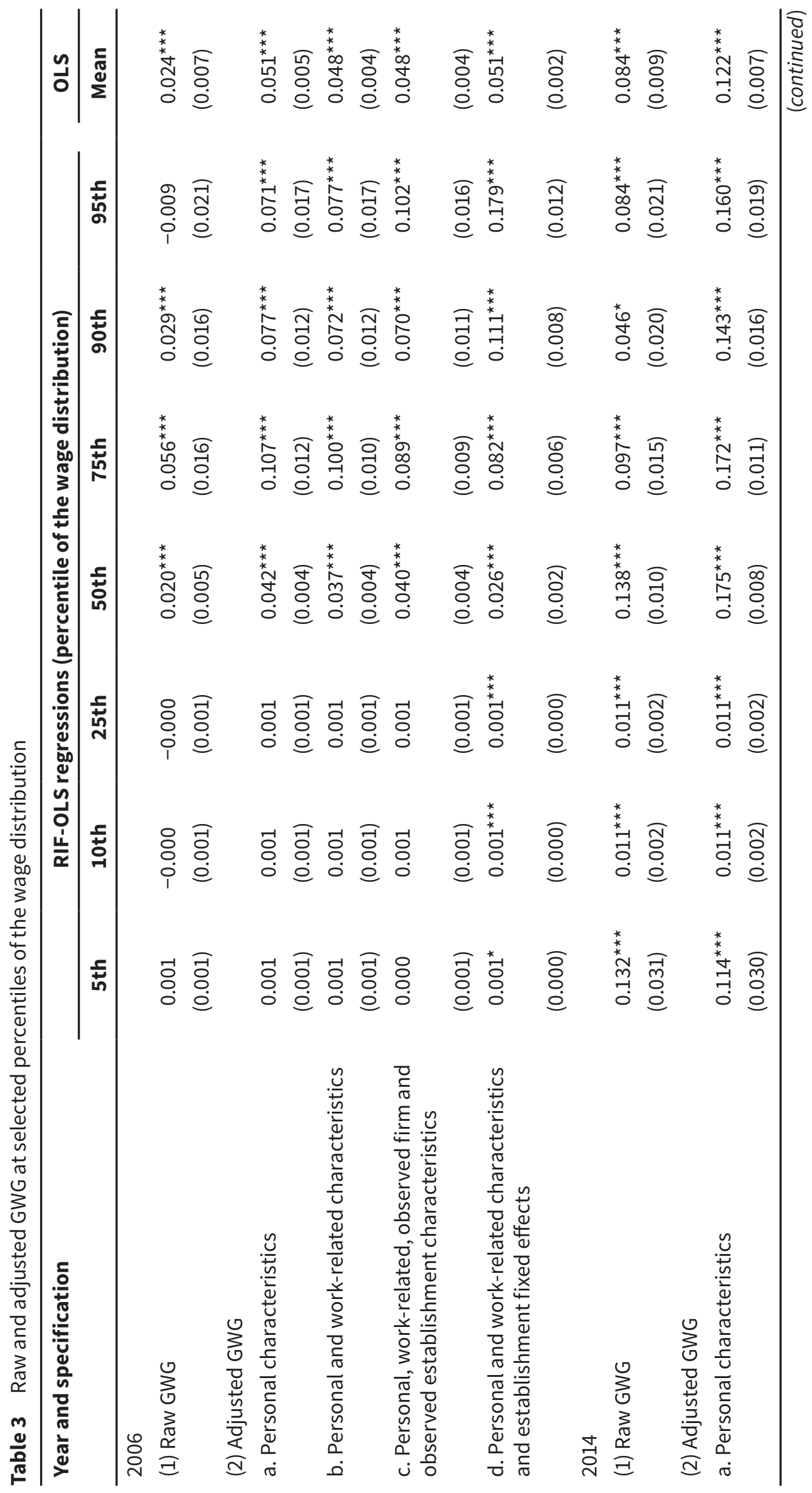




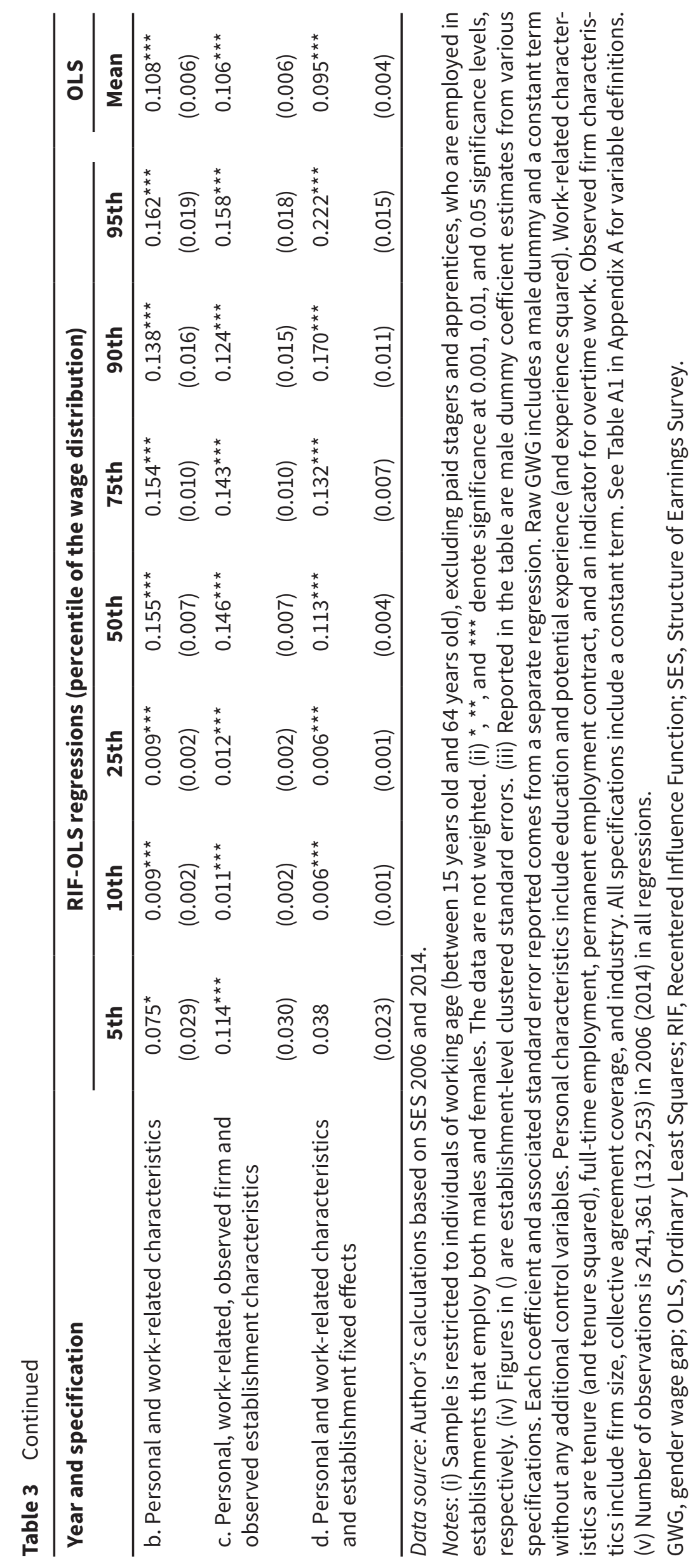


becomes more pronounced as we move up the distribution, then the GWG would be larger at the top than in the middle or bottom, which is consistent with the presence of a glass-ceiling effect. However, if women face larger wage differentials at the bottom of the wage distribution than at the upper percentiles or in the middle, this indicates the presence of a sticky-floor effect.

In Table 3, the first row of the upper panel (Specification (1)) shows an insignificant raw GWG in 2006 below the median of the wage distribution. At and above the median, however, women face a significant gap, at least until the 90th percentile. Once we control for personal characteristics (Specification (2a)), the GWG turns to be larger in magnitude at and above the median and becomes significant at the top of the distribution. This implies that, although women at and above the median of the wage distribution have superior productivity-related characteristics than their male counterparts, they face a larger GWG. After including work-related characteristics (Specification (2b)) and observed firm and establishment characteristics (Specification (2c)), the largest GWG remains among highly paid men and women, who are otherwise comparable. The results of Specification (2d) also reveal that females in Turkey also face a substantial within-establishment glass-ceiling effect, with a widening GWG as we move up the wage distribution. In fact, the withinestablishment gap widens around $11.0(\mathrm{log})$ percentage points between the 10th and 90th percentiles of the wage distribution, while the comparable figure is only around $7.1(\log )$ percentage points for the economy-wide GWG (Specification (2b)). This brings into question the mechanisms within establishments that give rise to the economy-wide glass-ceiling effect that women face.

The results presented in the lower panel of Table 3 display similar patterns, but they also show an increase in the GWG from 2006 to 2014 at all percentiles of the wage distribution, particularly at the bottom end of the distribution. This becomes more apparent in Figure 3, where we plot the adjusted GWG estimated from Specifications (2a)-(2d) for both years along with associated 95\% confidence intervals (CI) for the mean and at selected percentiles of the wage distribution. The increase in the adjusted GWG is particularly substantial at the bottom end of the distribution and at and above the median. Although the increase at the bottom end turns to be insignificant once the establishment fixed effects are controlled for (Specification (2d)), the results from 2014 highlight the importance of the within-establishment glass-ceiling effect, which widens by around $16.4(\mathrm{log})$ percentage points between the 10th and 90th percentiles of the wage distribution, while the economy-wide comparable figure (Specification (2b)) is only around $12.9(\log )$ percentage points (see Table 3$)$. These results also reinforce the importance of distributional analysis where we observe a more pronounced GWG at the median and upper tail of the wage distribution, which is neglected when the analysis focuses exclusively on the mean.

We explore the sensitivity of these results to using alternative samples and model specifications by restricting the sample to 18-64 years, including additional controls such as occupation, region of establishment (only available in 2014), more detailed industry; excluding overtime dummy; and to using weighted data in the regressions. As an additional sensitivity check, we also explore the influence of the method by using the conditional quantile regression approach of Koenker and Bassett (1978). These results, which are presented in Tables B9 and B10 in Appendix B, show that our key findings are robust, with an increase in the economy-wide 
Figure 3 Adjusted GWG at the mean and selected percentiles of the wage distribution.

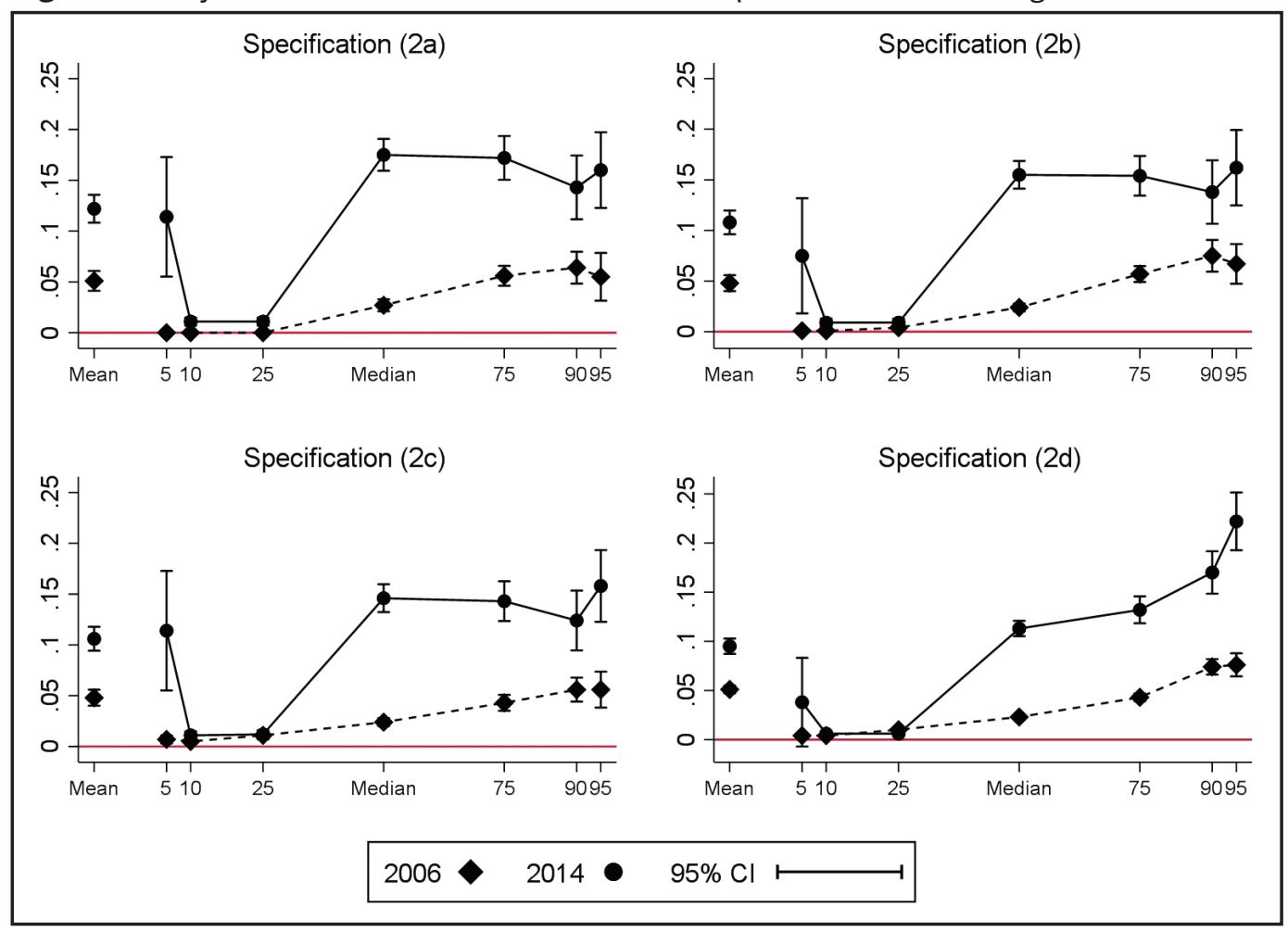

Data source: Author's calculations based on the SES 2006 and 2014.

Notes: (i) Sample is restricted to individuals of working age (between 15 years old and 64 years old), excluding paid stagers and apprentices, who are working in establishments that employ both males and females. The data are not weighted. (ii) Each coefficient estimate and associated $95 \% \mathrm{Cl}$ come from a separate regression. Specifications (2a)-(2d) are as set out in the text. Point estimates are provided in Table 3. Cl, confidence interval; GWG, gender wage gap; SES, Structure of Earnings Survey.

adjusted GWG across the distribution from 2006 to 2014 and a wider GWG at the median and upper tail of the wage distribution in both years, both of which are mainly driven by mechanisms that operate within establishments.

\subsection{Decomposition of the GWG across the distribution}

Parallel to our analysis at the mean, in this section, we decompose the raw GWG at different points of the wage distribution into its explained and unexplained components using the $\mathrm{BO}$ decomposition that relies on the RIF regression (RIF-BO decomposition) proposed by Firpo et al. (2009). In implementing the RIF-BO decomposition, we first run the RIF-OLS regression at each quantile and then perform the usual BO decomposition. This approach, as opposed to other decomposition methods that rely on conditional quantile regression (e.g., Machado and Mata, 2005 and Melly, 2005), is less computationally demanding and allows for a detailed decomposition to be carried out yielding an unconditional quantile decomposition (Fortin et al., 2011).

Figures 4 and 5 present these results for 2006 and 2014, respectively. Parallel to the analysis at the mean, in each figure, we present the decomposition results performed by estimating Specifications $(2 \mathrm{a})-(2 \mathrm{~d})$ separately for males and females for each year at selected points 
Figure 4 Decomposition of the GWG at selected percentiles of the wage distribution, 2006.

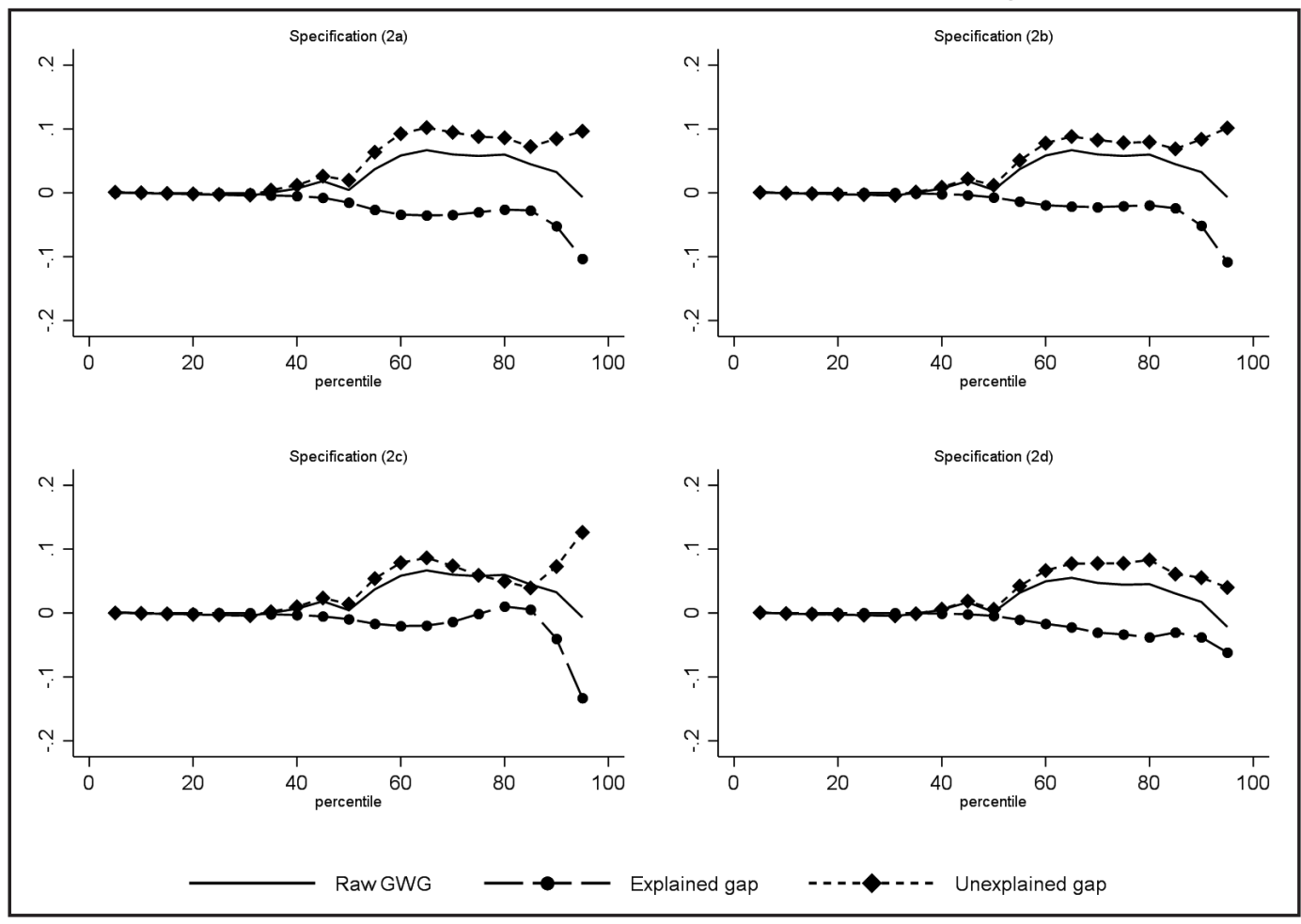

Data source: Author's calculations based on the SES 2006.

Notes: (i) Specifications (2a)-(2d) are as set out in the text. (ii) RIF-BO method is used to decompose the GWG using male coefficients as the baseline. (iii) "Explained gap" is that part of the raw GWG that is due to gender differences in productivity-related characteristics included in the specification. "Unexplained gap" is that part of the raw GWG that remains unexplained after controlling for the productivity-related characteristics. BO, Blinder-Oaxaca; GWG, gender wage gap; RIF, Recentered Influence Function; RIF-BO, BO decomposition that relies on the RIF regression; SES, Structure of Earnings Survey.

of the wage distribution. ${ }^{15}$ Consistent with the findings from the pooled model, Figure 4 shows a zero raw GWG in 2006, at least until the 40th percentile, after which there is a slight increase. ${ }^{16}$ Above this point, in all specifications, the GWG is almost entirely due to gender differences in returns to observed characteristics and thus remains unexplained. ${ }^{17}$ The unexplained gap widens as we move up the wage distribution, indicating the presence of a glass-ceiling effect. At the same time, the explained part of the GWG becomes negative and larger in absolute value as we move up the wage distribution, which partially offsets the effect of the gender differences in returns to characteristics. While the unexplained gap at different points of the wage distribution narrows slightly with the inclusion of establishment fixed

15 All the point estimates and standard errors are available upon request.

16 Below the 40th percentile, the only exceptions are the 6 th, 7 th and 33 rd percentiles of the wage distribution where the raw GWG is statistically different from zero.

17 The only exception is Specification (2c), where between the 77th and 80th percentiles of the wage distribution, the GWG is partly driven by gender differences in characteristics. Nevertheless, the main driver of the GWG remains to be the unexplained gap at these points accounting for $>70 \%$ of the GWG. 
Figure 5 Decomposition of the GWG at selected percentiles of the wage distribution, 2014.

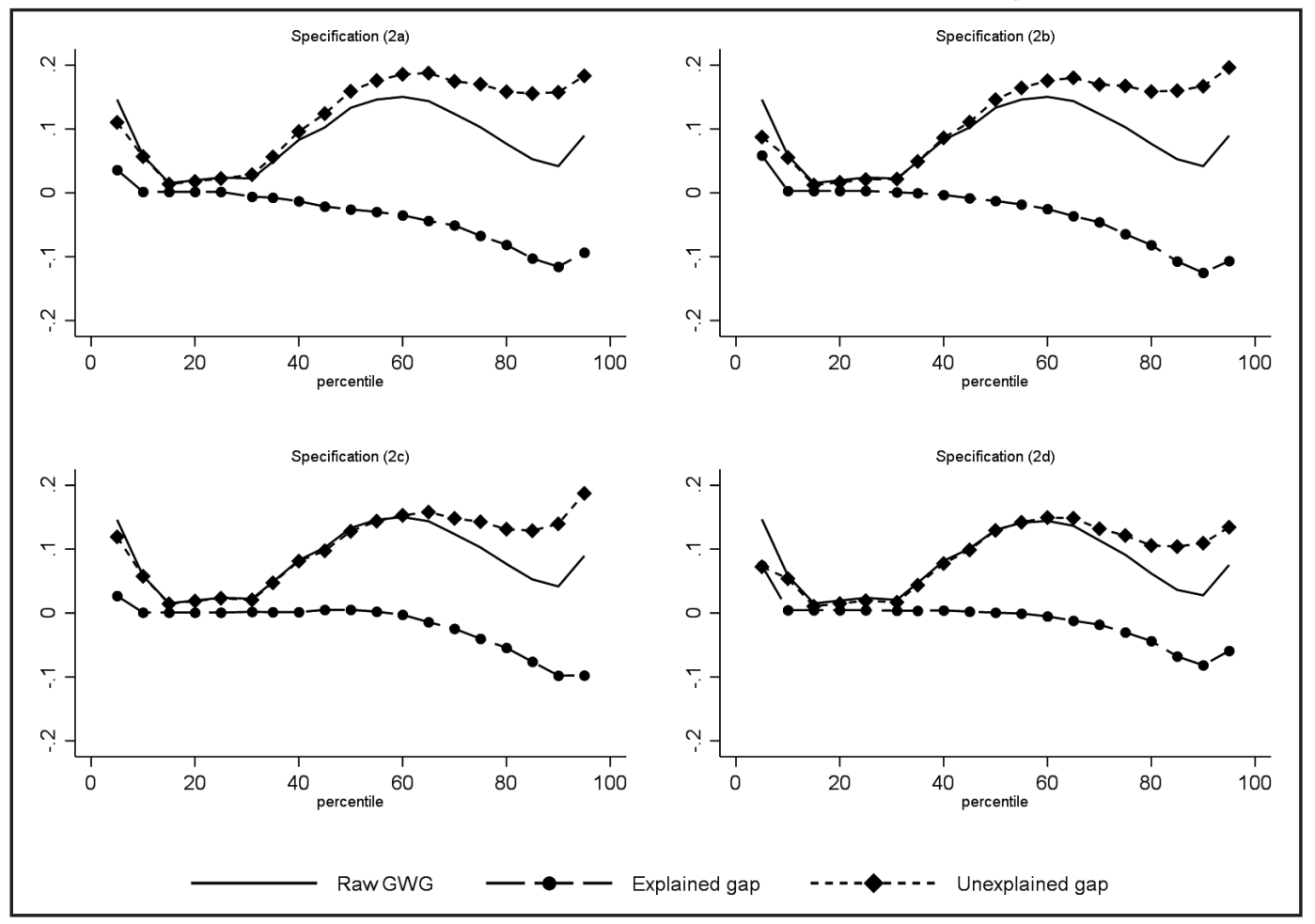

Data source: Author's calculations based on the SES 2014.

Notes: (i) Specifications (2a)-(2d) are as set out in the text. (ii) RIF-BO method is used to decompose the GWG using male coefficients as the baseline. (iii) "Explained gap" is that part of the raw GWG that is due to gender differences in productivity-related characteristics included in the specification. "Unexplained gap" is that part of the raw GWG that remains unexplained after controlling for the productivity-related characteristics. BO, Blinder-Oaxaca; GWG, gender wage gap; RIF, Recentered Influence Function; RIF-BO, BO decomposition that relies on the RIF regression; SES, Structure of Earnings Survey.

effects (Specification (2d)), particularly at the very top of the wage distribution, it remains as the main driver of the GWG. ${ }^{18}$

The results presented in Figure 5 display similar patterns, although the unexplained GWG is greater in 2014 than in 2006 across the entire distribution. ${ }^{19}$ This can be seen more clearly in Figure 6 where we plot the unexplained component of the GWG estimated from each specification for both years along with the associated 95\% CI. What is more striking is the dramatic increase in the GWG at the bottom end of the wage distribution. This is also true even after controlling for establishment fixed effects (Specification (2d)). In fact, a comparison of panels (2b) and (2d) of Figure 6 reveals that, except for the very top of the distribution in 2006, the unexplained gap remains virtually the same in both the years even after controlling for establishment fixed effects, suggesting that the largest portion of the economy-wide GWG in both years was mainly due to mechanisms that operate within establishments rather than between establishments across the distribution.

18 In particular, the economy-wide unexplained gap from Specification (2b) at the 90th percentile of the wage distribution exceeds the unexplained gap at the 50th percentile by $0.072 \mathrm{log}$ points, while the corresponding figure for withinestablishments from Specification (2d) is 0.049 log points.

19 The only exceptions are between the 26th and 33rd percentiles, where the unexplained gap in 2006 exceeds that in 2014 by around up to $6(\log )$ percentage points. 
Figure 6 Unexplained gap at selected percentiles of the wage distribution, 2006 and 2014.

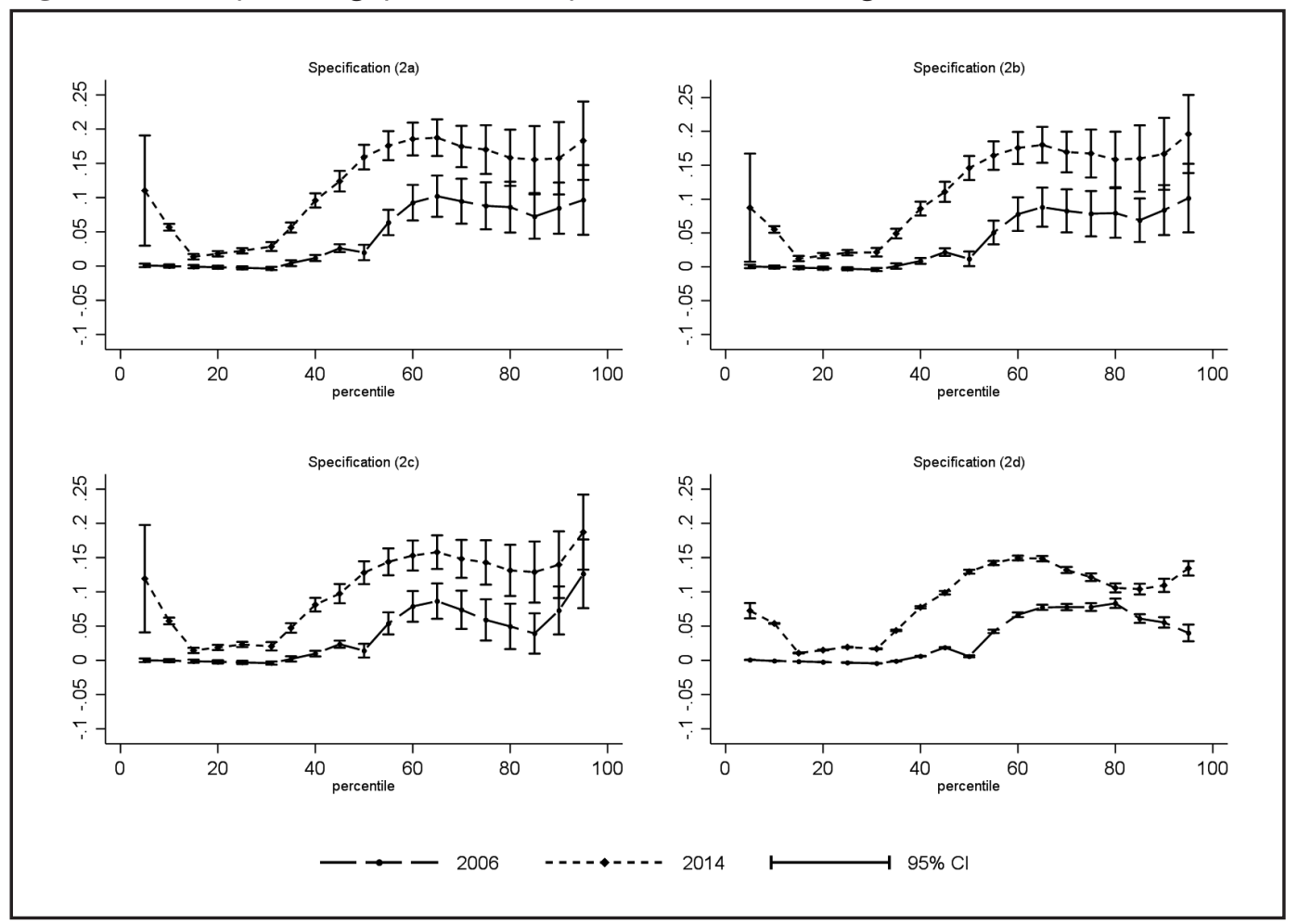

Data source: Author's calculations based on the SES 2006 and 2014.

Notes: (i) Specifications (2a)-(2d) are as set out in the text. (ii) Each point estimate and associated $95 \% \mathrm{Cl}$ are estimated using the RIF-BO method to decompose the GWG using male coefficients as the baseline. (iii) "Unexplained gap" is that part of the observed GWG that remains unexplained after controlling for the productivity-related characteristics included in each specification. BO, Blinder-Oaxaca; $\mathrm{Cl}$, confidence interval; GWG, gender wage gap; RIF, Recentered Influence Function; RIF-BO, BO decomposition that relies on the RIF regression; SES, Structure of Earnings Survey.

\section{Conclusions}

Using linked employer-employee data for Turkey, this paper investigates the GWG at different points of the wage distribution by exploring the role of firm-specific factors. Using well-established regression and decomposition methods, we find that the mean GWG among comparable men and women is much wider within establishments than between establishments. In fact, the largest portion of the economy-wide GWG arises from within-establishment gender wage differentials among otherwise comparable men and women.

Our distributional analysis reinforces the importance of within-firm gender wage inequalities, but also confirms that attention beyond the mean GWG is warranted. We find evidence of a glass-ceiling effect that women face in the Turkish labor market and that this effect is due mainly to mechanisms that operate within firms, rather than between establishments. We also find that, from 2006 to 2014, the GWG widened at all points of the wage distribution, especially among those in the lower part of the wage distribution. These results may be due in part to changing patterns in selection into employment for men and women as our analysis covers 
a period before and after the global economic crisis (see, for example, Dolado et al., 2020 for evidence from a range of European countries) and highlight the need for further investigation.

The results of this study also have important implications in terms of policy, as distinguishing within- and between-establishment GWGs would lead to different policy recommendations. As argued by Hara (2018), a more pronounced GWG between firms would require policies to promote equal opportunity in hiring practices, whereas targeting the elimination of barriers for females in accessing particular roles might be more effective if the GWG within firms was more pronounced. Policies that change the relative costs of female and male employees, such as the ones enacted by the Turkish government in the past two decades, may also influence within-firm gender pay inequalities. Although our results provide supporting evidence for an increase in the within-establishment GWG due to the policy-driven changes in the hiring costs of women, identifying a causal relationship goes beyond the scope of this study, and we leave it for future research.

\section{Abbreviations}

GWG, Gender Wage Gap; SES, Structure of Earnings Survey; BO, Blinder-Oaxaca; EU, European Union; TRY, Turkish Lira; OLS, Ordinary Least Squares; MM, Machado-Mata; PSM, Propensity Score Matching; RIF, Recentered Influence Function; ATT, Average Treatment Effect on the Treated; OECD, Organization for Economic Cooperation and Development.

\section{References}

Akhmedjonov, Alisher (2012): New Evidence on Pay Gap Between Men and Women in Turkey. Economics Letters 117(1), 32-34.

Albrecht, James; Andres Björklund; Susan Vroman (2003): Is There a Glass Ceiling in Sweden? Journal of Labor Economics 21(1), 145-177.

Aldan, Altan; Hatice B. G. Yunculer (2017): Decomposition of Real Wage Growth in Turkey. Research and Monetary Policy Department, Central Bank of the Republic of Turkey, Research Notes in Economics No. 1706

Anderson, Rachel (2017): Variations in Turkey's Female Labor Market: The Puzzling Role of Education. Doctoral Dissertation, Duke University.

Anker, Richard (1997): Theories of Occupational Segregation by Sex: An Overview. International Labour Review 136(3), 315-339.

Anxo, Dominique; Mattias Karlsson (2019): Overtime Work: A Review of Literature and Initial Empirical Analysis. International Labour Organization, Geneva.

Arulampalam, Wiji; Alison L. Booth; Mark L. Bryan (2007): Is There a Glass Ceiling over Europe? Exploring the Gender Pay Gap across the Wage Distribution. Industrial and Labor Relations Review 60(2), 163-186.

Atiyas, Izak; Ozan Bakıs; Yusuf K. Orhan (2017): Firm Dynamics and Job Creation in Turkey-Some Preliminary Results. REF Working Paper No 2017-1.

Auer, Peter; Sandrine Cazes (2000): The Resilience of the Long-term Employment Relationship: Evidence from the Industrialized Countries. International Labour Review 139(4), 379-408.

Balkan, Binnur; Seyit Cilasun; Belgi Turan (2016): The Impact of the Turkish Employment Subsidy Programs on Increasing the Level of Social Protection for Women. Economic Research Forum Working Paper No. 1022.

Bayard, Kimberly; Judith Hellerstein; David Neumark; Kenneth Troske (2003): New Evidence on Sex Segregation and Sex Differences in Wages from Matched Employer-Employee Data. Journal of Labor Economics 21(4), 887-922.

Blau, Francine D.; Lawrance M. Kahn (2017): The Gender Wage Gap: Extent, Trends, and Explanations. Journal of Economic Literature 55(3), 789-865.

Blinder, Alan S. (1973): Wage Discrimination: Reduced Form and Structural Variables. Journal of Human Resources 8(4), 436-455.

Bugra, Ayse (2012): The Changing Welfare Regime of Turkey: Neoliberalism, Cultural Conservatism and Social Solidarity Redefined, in: Dedeoglu, Saniye; Adem Yavuz Elveren (eds.), Gender and Society in Turkey: The Impact of Neoliberal Policies, Political Islam and EU Accession. London and New York: IB Tauris, 15-31. 
Card, David; Ana Rute Cardoso; Patrick Kline (2016): Bargaining, Sorting, and the Gender Wage Gap: Quantifying the Impact of Firms on the Relative Pay of Women. Quarterly Journal of Economics 131(2), 633-686.

Cardoso, Ana Rute; Paulo Guimarães; Pedro Portugal (2016): What Drives the Gender Wage Gap? A Look at the Role of Firm and Job-title Heterogeneity. Oxford Economic Papers 68(2), 506-524.

Cebeci, Tolga (2015): Gender Earnings Gap in the Formal Labor Market in Turkey. Washington DC: World Bank.

Chatterji, Monojit; Karen Mumford; Peter N. Smith (2011): The Public-Private Sector Gender Wage Differential: Evidence from Matched Employee-Workplace Data. Applied Economics 43(26), 3819-3833.

Dayioglu, Meltem; Murat G. Kirdar (2010): Determinants of and Trends in Labor Force Participation of Women in Turkey. State Planning Organization of the Republic of Turkey and World Bank, Welfare and Social Policy Analytical Work Program Working Paper No. 5.

De la Rica, Sara; Juan J. Dolado; Vanesa Llorens (2008): Ceilings or Floors? Gender Wage Gaps by Education in Spain. Journal of Population Economics 21(3), 751-776.

Dedeoglu, Saniye (2012): Equality, Protection or Discrimination: Gender Equality Policies in Turkey. Social Politics 19(2), 269-290.

Dedeoglu, Saniye (2013): Veiled Europeanisation of Welfare State in Turkey: Gender and Social Policy in the 2000s. Women's Studies International Forum 41(1), 7-13.

Dolado, Juan J.; Cecilia García-Peñalosa; Linas Tarasonis (2020): The Changing Nature of Gender Selection into Employment over the Great Recession. Economic Policy 35(104), 635-677.

Fernández-Kranz, Daniel; Núria Rodríguez-Planas (2011): The Part-time Pay Penalty in a Segmented Labor Market. Labour Economics 18(5), 591-606.

Firpo, Sergio; Nicole M. Fortin; Thomas Lemieux (2009): Unconditional Quantile Regressions. Econometrica 77(3), 953-973.

Fortin, Nicole; Thomas Lemieux; Sergio Firpo (2011): Decomposition Methods in Economics, in: Handbook of Labor Economics, Vol. 4a, Elsevier Inc., 1-102.

Gezici, Ferhan; Burcin Yazgi Walsh; Sinem Metin Kacar (2017): Regional and Structural Analysis of the Manufacturing Industry in Turkey. The Annals of Regional Science 59(1), 209-230.

Groshen, Erica L. (1991): The Structure of the Female/Male Wage Differential: Is it Who You Are, What You Do, or Where You Work? Journal of Human Resources 26(3), 457-472.

Hara, Hiromi (2018): The Gender Wage Gap across the Wage Distribution in Japan: Within- and BetweenEstablishment Effects. Labour Economics 53, 213-229.

Heckman, James J. (1979): Sample Selection Bias as a Specification Error. Econometrica 47(1), 153-161.

Hirsch, Boris; Marion König; Joachim Möller (2013): Is There a Gap in the Gap? Regional Differences in the Gender Pay Gap. Scottish Journal of Political Economy 60(4), 412-439.

Ilkkaracan, Ipek (2012): Why so few Women in the Labor Market in Turkey? Feminist Economics 18(1), 1-37.

Ilkkaracan, Ipek; Raziye Selim (2007): The Gender Wage Gap in the Turkish Labor Market. Labour 21(3), 563-593.

Javdani, Mohsen (2015): Glass Ceilings or Glass Doors? The Role of Firms in Male-Female Wage Disparities. Canadian Journal of Economics 48 (2), 529-560.

Jewell, Sarah Louse; Giovanni Razzu; Carl Singleton (2020): Who Works for Whom and the UK Gender Pay Gap. British Journal of Industrial Relations 58(1), 50-81.

Koenker, Roger; Gilbert Bassett (1978): Regression Quantiles. Econometrica 46(1), 33-50.

Machado, José A. F.; José Mata (2005): Counterfactual Decomposition of Changes in Wage Distributions Using Quantile Regression. Journal of Applied Econometrics 20(4), 445-465.

Magda, Iga; Katarzyna Salach (2019): Gender Pay Gap Patterns in Domestic and Foreign-Owned Firms. IZA Discussion Paper No. 12453.

Meara, Katie; Francesco Pastore; Allan Webster (2020): The Gender Pay Gap in the USA: A Matching Study. Journal of Population Economics 33(1), 271-305.

Melly, Blaise (2005): Decomposition of Differences in Distributions Using Quantile Regression. Labour Economics 12(4), 577-590.

Mumford, Karen; Peter N. Smith (2009): What Determines the Part-time and Gender Earnings Gaps in Britain: Evidence from the Workplace. Oxford Economic Papers 61, i56-i75.

Mundlak, Yair (1978): On the Pooling of Time Series and Cross Section Data. Econometrica 46(1), 69-85.

Oaxaca, Ronald L. (1973): Male-Female Wage Differentials in Urban Labor Markets. International Economic Review 14(3), 693-709.

OECD (2017): The Pursuit of Gender Equality: An Uphill Battle. Paris: OECD Publishing.

OECD (2019): Labour Force Participation Rate (Indicator). doi: 10.1787/8a801325-en [Accessed: 11 February 2019]. 
OECD (2021): Working Age Population (Indicator). doi: 10.1787/d339918b-en [Accessed: 17 March 2021].

Olivetti, Claudia; Barbara Petrongolo (2008): Unequal Pay or Unequal Employment? A Cross-Country Analysis of Gender Gaps. Journal of Labor Economics 26(4), 621-654.

Peetz, David; Georgina Murray (2017): Women, Labor Segmentation and Regulation: Varieties of Gender Gaps. New York, Palgrave Macmillan.

Reilly, Kevin T.; Tony S. Wirjanto (1999): Does More Mean Less? The Male/Female Wage Gap and the Proportion of Females at the Establishment Level. Canadian Journal of Economics 32(4), 906-929.

Sorensen, Elaine (1990): The Crowding Hypothesis and Comparable Worth. Journal of Human Resources 25(1), 55-89.

Suits, Daniel B. (1984): Dummy Variables: Mechanics v. Interpretation. The Review of Economics and Statistics 66(1), 177-180.

Tansel, Aysit (2005): Public-Private Employment Choice, Wage Differentials and Gender in Turkey. Economic Development and Cultural Change 53(2), 453-477.

Yucel, Yelda (2015): Response to the Crisis and Gender Segregation in Turkey's Labour Market. The Economic and Labour Relations Review 26(2), 276-295.

Yun, Myeong-Su (2005): A Simple Solution to the Identification Problem in Detailed Wage Decompositions. Economic Inquiry 43(4), 766-772.

World Bank (2006): Turkey: Labour Market Study Report No. 33254-TR. Washington DC: World Bank Group.

World Bank (2009): Female Labor Force Participation in Turkey: Trends, Determinants, and Policy Framework. Washington DC: World Bank. 


\section{Appendix}

\section{Appendix A. Data Appendix}

This study uses data from a linked employer-employee dataset, the Turkish Structure of Earnings Survey (SES). The SES is carried out regularly by the Turkish Statistical Institute (TurkStat) at four-yearly intervals beginning from 2006 and is conducted in accordance with Eurostat guidelines. The SES results published by Eurostat allow comparisons for all Member States of the EU, in the EU candidate countries and the European Free Trade Association countries. On the national level, the results are published in various TurkStat publications.

The main aim of the survey is to provide detailed information on the earnings from and hours in formal employment by personal and work-related characteristics of employees, as well as by firm and establishment characteristics. As such, the SES includes information provided by the employer on contractual working hours per week, monthly paid hours, hourly average gross wage, monthly average basic and gross wage of workers. It also provides information on key personal and work-related characteristics of employees, such as gender, age, educational attainment, tenure, full-time/part-time status, type of contract (permanent or temporary), as well as information on the occupation. It also includes information on firm and establishment characteristics, including the size of the firm to which the establishment belongs (in terms of number of employees), the economic activity and collective agreement coverage at the establishment level, and region of the establishment (only available in 2014). Table A1 presents full definitions of all variables included in this study.

Table A1 Variable definitions

\begin{tabular}{|c|c|c|}
\hline Variable & Type & Definition \\
\hline $\begin{array}{l}\text { Log hourly } \\
\text { gross wage }\end{array}$ & Continuous & $\begin{array}{l}\text { Constructed by the author: the monthly gross wage } \\
\text { (the sum of monthly basic wages, overtime payments, } \\
\text { payments for shift work/night work, and other regular } \\
\text { payments paid to employees) in the reference month } \\
\text { divided by monthly paid hours (the sum of contractual } \\
\text { working hours pertaining to basic wage and overtime } \\
\text { hours worked) during the reference month (deflated using } \\
\text { the Consumer Price Index base year 2003, in } 2003 \text { TRY) }\end{array}$ \\
\hline Gender & Binary & $\begin{array}{l}\text { Recoded by the author as follows: } \\
\left\{\begin{array}{lc}0 & \text { female } \\
1 & \text { male }\end{array}\right.\end{array}$ \\
\hline $\begin{array}{l}\text { Educational } \\
\text { attainment }\end{array}$ & Categorical & $\begin{array}{l}\text { The highest successfully completed level of education } \\
\text { which the employee has received according to the Inter- } \\
\text { national Standard Classification of Education (ISCED } 97 \text { in } \\
2006 \text { and ISCED } 2011 \text { in 2014). } \\
\left\{\begin{array}{l}1 \text { primary school and below } \\
2 \text { primary education and secondary eduction } \\
3 \text { high school } \\
4 \text { vocational high school } \\
5 \text { higher education }\end{array}\right.\end{array}$ \\
\hline
\end{tabular}


Table A1 Continued

\begin{tabular}{|c|c|c|}
\hline Variable & Type & Definition \\
\hline $\begin{array}{l}\text { Potential } \\
\text { labor market } \\
\text { experience }\end{array}$ & Continuous & $\begin{array}{l}\text { Constructed by the author: age-years of schooling-6. Years } \\
\text { of schooling are taken as } 5 \text { years for primary school and } \\
\text { below, } 8 \text { years for primary education and secondary edu- } \\
\text { cation, } 11 \text { years for high school and vocational high school, } \\
\text { and } 14 \text { years for higher education following Cebeci (2015). }\end{array}$ \\
\hline Tenure & Continuous & $\begin{array}{l}\text { The total length of service in the firm to which the estab- } \\
\text { lishment belongs in the reference month (in years). }\end{array}$ \\
\hline $\begin{array}{l}\text { Full-time em- } \\
\text { ployment }\end{array}$ & Binary & $\begin{array}{l}\text { Contractual working time. Recoded by the author as: } \\
\begin{cases}0 & \text { if part-time } \\
1 & \text { if full time }\end{cases} \end{array}$ \\
\hline $\begin{array}{l}\text { Type of } \\
\text { employment } \\
\text { contract }\end{array}$ & Binary & $\begin{array}{l}\text { Type of employment contract of the worker. Recoded by } \\
\text { the author as: } \\
\begin{cases}0 & \text { if temporary (fixed-term) contact } \\
1 & \text { if permanent contact }\end{cases} \end{array}$ \\
\hline $\begin{array}{l}\text { Overtime } \\
\text { work }\end{array}$ & Binary & $\begin{array}{l}\text { Constructed by the author based on the monthly hours of } \\
\text { overtime work during the reference month. Recoded by } \\
\text { the author as: } \\
\begin{cases}0 & \text { if total monthly hours of overtime work is zero } \\
1 & \text { if total monthly hours of overtime work greater than zero }\end{cases} \end{array}$ \\
\hline Firm size & Categorical & $\begin{array}{l}\text { Size of the firm (in terms of number of employees) to } \\
\text { which the establishment belongs. } \\
\begin{cases}1 & \text { if } 10-49 \\
2 & \text { if } 50-249 \\
3 & \text { if } 250-499 \\
4 & \text { if } 500-999 \\
5 & \text { if } 1000 \text { and more }\end{cases} \end{array}$ \\
\hline $\begin{array}{l}\text { Collective } \\
\text { agreement } \\
\text { coverage }\end{array}$ & Binary & $\begin{array}{l}\text { Collective agreement coverage of the establishment. } \\
\text { Recoded by the author as: } \\
\begin{cases}0 & \text { if no collective pay aggrement exists in the establishment } \\
1 & \text { otherwise }\end{cases} \end{array}$ \\
\hline Industry & Categorical & $\begin{array}{l}\text { Principal economics activity of the establishment coded } \\
\text { according to the Statistical Classification of Economic } \\
\text { Activities in the European Community (NACE Rev. } 1.1 \text { in } \\
2006 \text { and NACE Rev. } 2 \text { in 2014). Recoded by the author at } \\
\text { section level according to NACE Rev. } 2 \text { (12 categories). }\end{array}$ \\
\hline Occupation & Categorical & $\begin{array}{l}\text { Occupation of the employee in the reference month coded } \\
\text { according to the ISCO88 in } 2006 \text { and ISCO } 08 \text { in 2014. Recod- } \\
\text { ed by the author at one-digit ISCO } 08 \text { level ( } 9 \text { categories) }\end{array}$ \\
\hline Region $^{b}$ & Categorical & $\begin{array}{l}\text { Region of the establishment codded according to the } \\
\text { NUTS-1 - only available in } 2014 \text { ( } 12 \text { categories) }\end{array}$ \\
\hline
\end{tabular}

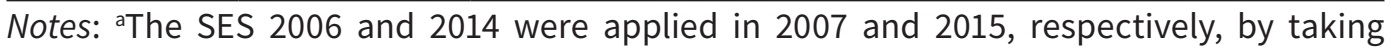
November as a reference month since it was a month without seasonal payments and absences.

bInformation on region is provided only with the SES 2014 microdata.

ISCO, International Standard Classification of Occupations; NUTS, Nomenclature of Territorial Units for Statistics; SES, Structure of Earnings Survey; TRY, Turkish Lira. 
In terms of sampling and data collection, the SES adopts a two-stage stratified random sampling method. In the first stage, establishments of firms with at least 10 employees in the covered areas of economic activity in the Business Registrar are selected. ${ }^{20,21}$ The distribution of the sample size for establishments was realized based on the level of statistical region units, economic activity, and the size band of the firm that the establishment is associated with. In the second stage, a random sample of all employees who work for wage as employee, stager or apprentice employed from the selected establishments was selected by ordering alphabetically the last names of all employees within each establishment and selecting the required number of employees from these lists systematically. The required number of employees to be included in the sample for each establishment was selected through a proportional to (establishment) size sampling scheme (see Table A2). For each establishment, the sample weights (named as grossing-up factor) for employees, based on (number of employees in enterprise)/(number of employees in sample) is provided.

The data were collected through regional offices of the TurkStat using methods complementing each other, such as mail, face-to-face interviews, and electronic mail for 2006, while a web-based application was used for the 2014 survey. The reporting unit in the SES is the establishment that fills out a questionnaire and provides the information to be collected.

The SES data covers paid employees in firms with at least 10 employees in the covered areas of economic activity. However, it does not cover workers from small-size firms (i.e., with $<10$ employees), neither workers employed in informal sector. To understand the extent of the SES coverage, Table A3 compares the total annual employment numbers from the SES

Table A2 Number of employees to be sampled in establishments (SES second stage of sampling) by size band of the establishment

\begin{tabular}{lc}
\hline Establishment size band & Number of employees to be sampled \\
\hline $1-19$ & All \\
$20-49$ & 20 \\
$50-99$ & 25 \\
$100-299$ & 35 \\
$250-499$ & 40 \\
$500-999$ & 50 \\
$1,000-2,499$ & 75 \\
$2,500-4,999$ & 125 \\
5,000 and over & 150 \\
\hline
\end{tabular}

Source: The SES 2006 and 2014 Quality Reports. Available at https://ec.europa.eu/ eurostat/cache/metadata/en/earn_ses06_esms.htm and https://ec.europa.eu/eurostat/ cache/metadata/EN/earn_ses2014_esms.htm.

SES, Structure of Earnings Survey.

20 The SES 2006 covers all economic activities defined in sections C to K and M to O of the International Standards of Economic Activities in the European Union (NACE Rev. 1.1). In 2010, the classification systems for economic activities (and occupations) changed for all EU member states from NACE Rev.1.1 to NACE Rev.2 (and from ISCO-88 to ISCO08). Thus, the SES 2014 covers economic activities defined in sections B to S excluding O of International Standards of Economic Activities in the European Union (NACE Rev. 2).

21 The Business Register is a census of firms and is updated annually by TurkStat based on the information obtained from the Ministry of Finance and Annual Structural Business Survey results. It covers all firms in formal economy, and has information on the sector of activity, the year that firms were established and/or year that the firm started operations, and the number of employees. 
Table A3 SES sample coverage by year

\begin{tabular}{|c|c|c|c|c|c|c|c|}
\hline Year & $\begin{array}{c}\text { SES }^{\mathrm{a}} \\
\text { Total number } \\
\text { of employees }^{\mathrm{b}} \\
\text { (1) }\end{array}$ & $\begin{array}{c}\text { HLFS }^{c} \\
\text { Total } \\
\text { employment } \\
(2)\end{array}$ & $\begin{array}{c}\text { HLFS } \\
\text { Total number } \\
\text { of employees } \\
\text { (formal and } \\
\text { informal) } \\
\text { (3) }\end{array}$ & $\begin{array}{c}\text { HLFS } \\
\text { Total number } \\
\text { of employees } \\
\text { (formal) } \\
\text { (4) }\end{array}$ & $(3) /(2)$ & $(4) /(3)$ & $(1) /(4)$ \\
\hline 2006 & $5,986,247$ & $20,423,000$ & $12,028,000$ & $8,242,000$ & 0.59 & 0.69 & 0.73 \\
\hline 2014 & $9,651,017$ & $25,932,000$ & $17,125,000$ & $13,777,000$ & 0.66 & 0.80 & 0.70 \\
\hline
\end{tabular}

Notes: ${ }^{a}$ Author's calculation based on the SES 2006 and 2014.

bTotal number of employees is calculated by using the grossing up factor for employees.

'Author's own elaboration based on Aslan, Gurdal (2019): The Number of Minimum Wage Workers and the Change in Wage Levels (2003-2017) Household Labour Force Surveys Data Analysis. Journal of Social Security 9(1), 141-159.

HLFS, Household Labour Force Survey; SES, Structure of Earnings Survey.

(column 1) with those from the Household Labour Survey (HLFS) (column 2), the largest and nationally representative Turkish household survey, which also includes self-employed, unpaid family workers, as well as employees working in small-size enterprises (i.e., with $<10$ employees) and in sectors that are not covered by the SES. Based on the HLFS column (3) of Table A3 presents the total number of employees working in both formal and informal economy, while column (4) is the number of employees in formal economy including those employed in sectors and small size enterprises. Column titled (3)/(2) shows that about $59-66 \%$ of the total workforce in Turkey falls in the category of wage/salary employment, while column (4)/(3) suggests that the formal sector employees constitute the main part (with a share of $69 \%$ in 2006 and $80 \%$ in 2014) of the wage/salary employment. A comparison of the total number of employees in the SES and the HLFS is provided in the last column ((1)/(4)). According to these figures, the SES, which does not cover paid employees in firms with $<10$ employees and in agriculture, fishing, public administration, private households, and extra-territorial organizations, accounts for around $70 \%$ of the wage/salary employment in the formal sector in both years. 


\section{Appendix B. Additional tables and figures}

Table B1 List of selected gender equality policies, Turkey 2000-2018

\begin{tabular}{|c|c|c|}
\hline Year & Policy & Description \\
\hline 2001 & $\begin{array}{l}\text { Amendment to the } \\
\text { Constitution } \\
\text { (Article } 41 \text { ) }\end{array}$ & $\begin{array}{l}\text { Added "based on the equality between spouses" to } \\
\text { the previous version of the article, which stated that } \\
\text { "Family is the foundation of the Turkish society". }\end{array}$ \\
\hline 2002 & $\begin{array}{l}\text { New Civil Code } \\
\text { (Law no: 4721) }\end{array}$ & $\begin{array}{l}\text { Increased the legal marriage age to } 18 \text { for men (from 17) } \\
\text { and women (from 15); established the equality of men } \\
\text { and women in the family, including abolishment of the } \\
\text { term "head of household" and of needing the permis- } \\
\text { sion of spouses to work; introduced the legal basis for } \\
\text { the sharing of marital assets in case of divorce; granted } \\
\text { the same heredity rights to children born out of wed- } \\
\text { lock as to those of legitimate birth. }\end{array}$ \\
\hline 2003 & $\begin{array}{l}\text { New Labor Law } \\
\text { (Law no: 4857) }\end{array}$ & $\begin{array}{l}\text { Set the legal basis for equal pay for equal work; } \\
\text { reinforced the equal treatment principle for women } \\
\text { and men; decreased the restrictions on temporary } \\
\text { employment; provided a legal basis for atypical em- } \\
\text { ployment; lifted the ban on employment of women in } \\
\text { night shifts of manufacturing establishments; extend- } \\
\text { ed paid maternity leave from } 12 \text { weeks to } 16 \text { weeks } \\
\text { ( } 8 \text { weeks before and } 8 \text { weeks after childbirth); intro- } \\
\text { duced breastfeeding leave to a total of one and a } \\
\text { half hours for mothers of children below the age of } \\
\text { one; obliged companies employing } 100-150 \text { female } \\
\text { workers to provide comprehensive nursery rooms for } \\
\text { children under the age of one and companies employ- } \\
\text { ing >150 female workers to provide comprehensive } \\
\text { childcare centers and pre-school facilities for children } \\
\text { under the age of six. }\end{array}$ \\
\hline 2003 & $\begin{array}{l}\text { Family Court Law } \\
\text { (Law no: 4787) }\end{array}$ & $\begin{array}{l}\text { Established Family Courts in districts with }>100,000 \\
\text { population to enforce the Civil Code and ensure gender } \\
\text { equality. }\end{array}$ \\
\hline 2004 & $\begin{array}{l}\text { Amendments to the } \\
\text { Constitution } \\
\text { (Articles } 10 \text { and 90) }\end{array}$ & $\begin{array}{l}\text { Amendments to Article } 10 \text { reinforced equal rights of } \\
\text { women and men and emphasized the responsibility of } \\
\text { the State to ensure equality. Amendments to Article } 90 \\
\text { ensured the supremacy of international laws (including } \\
\text { the Convention on the Elimination of All Forms of Dis- } \\
\text { crimination against Women in } 1985 \text { and the European } \\
\text { Social Charter in 1996) in the case of a conflict between } \\
\text { Turkish law and international treaties with regards to } \\
\text { human rights. }\end{array}$ \\
\hline 2005 & $\begin{array}{l}\text { New Penal Code } \\
\text { (Law no: } 5237 \text { ) }\end{array}$ & $\begin{array}{l}\text { Defined sexual harassment in work; reinforced prohibi- } \\
\text { tion of gender-based discrimination. }\end{array}$ \\
\hline 2006 & $\begin{array}{l}\text { Social Insurance and } \\
\text { General Health Insur- } \\
\text { ance Act } \\
\text { (Law no: } 5510 \text { ) }\end{array}$ & $\begin{array}{l}\text { Merged different security systems into one structure; } \\
\text { adopted harmonized legislation for maternity and } \\
\text { breastfeeding leaves and for the pension plans regulat- } \\
\text { ing the working conditions for women. }\end{array}$ \\
\hline
\end{tabular}


Table B1 Continued

\begin{tabular}{|c|c|c|}
\hline Year & Policy & Description \\
\hline 2008 & $\begin{array}{l}\text { Employment Package } \\
\text { (Law no: } 5763 \text { ) }\end{array}$ & $\begin{array}{l}\text { Introduced a direct employment subsidy program (with } \\
\text { a limit that corresponds to the minimum wage level) } \\
\text { with a one-year participation period (extended to June } \\
\text { 30, } 2010 \text {, with Law 5838) by reducing the employers' } \\
\text { contribution to social security payment of new hires } \\
\text { for } 5 \text { years, covering } 100 \% \text { of social security payments } \\
\text { of new employees for the first year and reducing its } \\
\text { participation by } 20 \% \text { each year for the following } 4 \text { years. } \\
\text { Targeted young men (ages between } 18 \text { and } 29 \text { ) and } \\
\text { women > } 18 \text { who were not employed as a tax-registered } \\
\text { workers in the preceding } 6 \text { months. }\end{array}$ \\
\hline 2010 & $\begin{array}{l}\text { Amendment to the } \\
\text { Constitution } \\
\text { (Article 10) }\end{array}$ & $\begin{array}{l}\text { Added "Measures taken for this purpose shall not be } \\
\text { interpreted as contrary to the principle" to Article } 10 .\end{array}$ \\
\hline 2011 & $\begin{array}{l}\text { Amendments to the } \\
\text { Labor Law } \\
\text { (Law No. 6111) }\end{array}$ & $\begin{array}{l}\text { Enforced the rules of maternity leave for women } \\
\text { (mandatory for } 16 \text { weeks and fully paid by the social } \\
\text { security system); introduced the right to use paid leaves } \\
\text { for breastfeeding; ruled out terminating job contracts } \\
\text { on grounds of pregnancy; brought new regulations for } \\
\text { part-time work; incorporated domestic help workers } \\
\text { into the social security system; extended maternity } \\
\text { leave to } 12 \text { months for civil servants and } 6 \text { months for } \\
\text { others on an unpaid basis; granted } 10 \text { days' voluntary } \\
\text { paid paternity leave to civil servants whose wives give } \\
\text { birth. } \\
\text { Extended the period (for the period between March } \\
2011 \text { and December } 2015 \text { ) and coverage (both men and } \\
\text { women of all ages and relaxing the subsidy limit cover- } \\
\text { ing the total social security payment amount regardless } \\
\text { of the wage level) of the } 2008 \text { employment subsidy } \\
\text { program. }\end{array}$ \\
\hline 2016 & $\begin{array}{l}\text { Amendments to the } \\
\text { Labor Law (Law no: } \\
6663 \text { ) }\end{array}$ & $\begin{array}{l}\text { Introduced unpaid maternity leave to mothers as half } \\
\text { of their weekly working hours for } 60 \text { days for the first } \\
\text { birth, } 120 \text { days for the second birth, and } 160 \text { days for } \\
\text { following births; introduced the right to request part- } \\
\text { time work for the period between when maternity leave } \\
\text { ends until the beginning of the month after the child's } \\
\text { compulsory education begins for both parents whose } \\
\text { spouse is also working; extended the coverage of ma- } \\
\text { ternity leave and the right to request part-time work to } \\
\text { couples or individuals adopting a child under } 3 \text { years' } \\
\text { old. }\end{array}$ \\
\hline
\end{tabular}

Sources: Anderson (2017), Balkan et al. (2016), Dedeoglu (2012), World Bank (2009). 
Table B2 Sample means for establishments

2006

2014

Firm and establishment characteristics

Firm size

$\begin{array}{lll}10-49 \text { employees } & 0.57 & 0.41 \\ 50-249 \text { employees } & 0.20 & 0.16 \\ \text { 250-499 employees } & 0.08 & 0.13 \\ 500-999 \text { employees } & 0.06 & 0.13 \\ 1000+\text { employees } & 0.10 & 0.16 \\ \text { llective agreement coverage of the establishment } & 4.74 & 0.05\end{array}$

Industry of the establishment

Manufacturing

$0.01 \quad 0.01$

Electricity, gas, and water supply

$0.35 \quad 0.24$

Construction

$0.02 \quad 0.02$

Wholesale and retail trade

$0.05 \quad 0.05$

Hotels and restaurants

$0.24 \quad 0.31$

Transport, storage, and communication

$0.05 \quad 0.06$

Financial intermediation

$0.08 \quad 0.05$

Real estate, renting and business activities

$0.06 \quad 0.05$

Education

$0.06 \quad 0.11$

Health and social work

$0.04 \quad 0.03$

Other social and personal service activities

$0.02 \quad 0.03$

$0.02 \quad 0.04$

Number of establishments

12,874

7,867

Data source: Author's calculations based on the SES 2006 and 2014.

Notes: Sample is restricted to individuals of working age (between 15 years old and 64 years old), excluding paid stagers and apprentices, who are employed in establishments that employ both males and females. The data are unweighted.

SES, Structure of Earnings Survey. 
Table B3 Sample means within establishments

\begin{tabular}{|c|c|c|c|c|c|c|}
\hline & \multicolumn{3}{|c|}{2006} & \multicolumn{3}{|c|}{2014} \\
\hline & All & Males & Females & All & Males & Females \\
\hline \multicolumn{7}{|l|}{ Personal characteristics } \\
\hline Male & 0.71 & - & - & 0.67 & - & - \\
\hline \multicolumn{7}{|l|}{ Educational attainment } \\
\hline Primary school and below & 0.26 & 0.28 & 0.17 & 0.16 & 0.16 & 0.15 \\
\hline $\begin{array}{l}\text { Primary education and } \\
\text { secondary school }\end{array}$ & 0.15 & 0.16 & 0.10 & 0.14 & 0.15 & 0.10 \\
\hline High school & 0.27 & 0.26 & 0.31 & 0.32 & 0.32 & 0.33 \\
\hline Vocational high school & 0.09 & 0.09 & 0.10 & 0.07 & 0.08 & 0.06 \\
\hline Higher education & 0.23 & 0.22 & 0.32 & 0.31 & 0.29 & 0.37 \\
\hline $\begin{array}{l}\text { Potential labor market } \\
\text { experience (years) }\end{array}$ & 16.68 & 17.66 & 14.25 & 17.09 & 17.74 & 15.76 \\
\hline \multicolumn{7}{|l|}{ Work-related characteristics } \\
\hline Tenure (years) & 3.20 & 3.29 & 2.93 & 2.86 & 2.97 & 2.61 \\
\hline Full-time & 0.99 & 0.99 & 0.99 & 0.98 & 0.98 & 0.98 \\
\hline Permanent contract & 0.97 & 0.97 & 0.97 & 0.94 & 0.94 & 0.95 \\
\hline Overtime work & 0.11 & 0.11 & 0.8 & 0.15 & 0.16 & 0.12 \\
\hline \multicolumn{7}{|l|}{ Occupation distribution } \\
\hline $\begin{array}{l}\text { Legislators, senior officials, and } \\
\text { managers }\end{array}$ & 0.07 & 0.08 & 0.06 & 0.06 & 0.08 & 0.05 \\
\hline Professionals & 0.08 & 0.07 & 0.12 & 0.10 & 0.10 & 0.13 \\
\hline $\begin{array}{l}\text { Technicians and associate pro- } \\
\text { fessionals }\end{array}$ & 0.18 & 0.17 & 0.20 & 0.09 & 0.09 & 0.08 \\
\hline Clerks & 0.14 & 0.01 & 0.28 & 0.17 & 0.13 & 0.28 \\
\hline $\begin{array}{l}\text { Service, shop and market sales' } \\
\text { workers }\end{array}$ & 0.13 & 0.14 & 0.11 & 0.26 & 0.25 & 0.26 \\
\hline $\begin{array}{l}\text { Skilled agricultural and fishery } \\
\text { workers }\end{array}$ & 0.00 & 0.00 & 0.00 & 0.00 & 0.00 & 0.00 \\
\hline $\begin{array}{l}\text { Craft and related trade } \\
\text { workers }\end{array}$ & 0.16 & 0.17 & 0.08 & 0.11 & 0.12 & 0.03 \\
\hline $\begin{array}{l}\text { Plant and machine operators } \\
\text { and assemblers }\end{array}$ & 0.11 & 0.13 & 0.04 & 0.09 & 0.11 & 0.04 \\
\hline Elementary occupations & 0.13 & 0.13 & 0.12 & 0.12 & 0.11 & 0.13 \\
\hline $\begin{array}{l}\text { Average number of employees } \\
\text { per establishment }\end{array}$ & 19 & 14 & 5 & 17 & 12 & 5 \\
\hline
\end{tabular}

Data source: Author's calculations based on the SES 2006 and 2014.

Notes: Sample is restricted to individuals of working age (between 15 years old and 64 years old), excluding paid stagers and apprentices, who are employed in establishments that employ both males and females. The data are unweighted.

SES, Structure of Earnings Survey. 
Table B4 Sample means across all establishments

\begin{tabular}{|c|c|c|c|c|c|c|}
\hline & \multicolumn{3}{|c|}{2006} & \multicolumn{3}{|c|}{2014} \\
\hline & All & Males & Females & All & Males & Females \\
\hline \multicolumn{7}{|l|}{ Personal characteristics } \\
\hline \multicolumn{7}{|l|}{ Educational attainment } \\
\hline Primary school and below & 0.27 & 0.31 & 0.19 & 0.17 & 0.19 & 0.15 \\
\hline Primary education and secondary school & 0.15 & 0.16 & 0.11 & 0.15 & 0.18 & 0.11 \\
\hline High school & 0.24 & 0.23 & 0.28 & 0.28 & 0.27 & 0.29 \\
\hline Vocational high school & 0.10 & 0.11 & 0.09 & 0.08 & 0.10 & 0.06 \\
\hline Higher education & 0.23 & 0.19 & 0.33 & 0.31 & 0.27 & 0.40 \\
\hline Potential labor market experience (years) & 17.09 & 18.23 & 14.01 & 17.40 & 18.30 & 15.32 \\
\hline \multicolumn{7}{|l|}{ Work-related characteristics } \\
\hline Tenure (years) & 3.67 & 3.92 & 3.03 & 3.18 & 3.39 & 2.70 \\
\hline Full-time & 0.99 & 0.99 & 0.99 & 0.98 & 0.98 & 0.98 \\
\hline Permanent contract & 0.96 & 0.96 & 0.97 & 0.93 & 0.94 & 0.93 \\
\hline Overtime work & 0.14 & 0.15 & 0.11 & 0.20 & 0.22 & 0.15 \\
\hline \multicolumn{7}{|l|}{ Firm and establishment characteristics } \\
\hline \multicolumn{7}{|l|}{ Firm size (number of employees) } \\
\hline $10-49$ & 0.46 & 0.46 & 0.46 & 0.32 & 0.32 & 0.32 \\
\hline $50-249$ & 0.24 & 0.24 & 0.24 & 0.19 & 0.20 & 0.18 \\
\hline $250-499$ & 0.10 & 0.10 & 0.10 & 0.17 & 0.17 & 0.17 \\
\hline $500-999$ & 0.08 & 0.08 & 0.08 & 0.16 & 0.16 & 0.17 \\
\hline $1000+$ & 0.12 & 0.12 & 0.11 & 0.15 & 0.15 & 0.16 \\
\hline $\begin{array}{l}\text { Collective agreement coverage of the } \\
\text { establishment }\end{array}$ & 0.10 & 0.12 & 0.06 & 0.10 & 0.12 & 0.08 \\
\hline \multicolumn{7}{|l|}{ Industry of the establishment } \\
\hline Mining and quarrying & 0.01 & 0.02 & 0.01 & 0.02 & 0.02 & 0.01 \\
\hline Manufacturing & 0.42 & 0.44 & 0.37 & 0.33 & 0.36 & 0.25 \\
\hline Electricity, gas, and water supply & 0.03 & 0.03 & 0.01 & 0.02 & 0.02 & 0.01 \\
\hline Construction & 0.04 & 0.05 & 0.02 & 0.04 & 0.04 & 0.02 \\
\hline Wholesale and retail trade & 0.19 & 0.19 & 0.20 & 0.23 & 0.23 & 0.23 \\
\hline Hotels and restaurants & 0.05 & 0.05 & 0.04 & 0.06 & 0.06 & 0.06 \\
\hline Transport, storage, and communication & 0.07 & 0.07 & 0.06 & 0.06 & 0.06 & 0.06 \\
\hline Financial intermediation & 0.04 & 0.03 & 0.07 & 0.04 & 0.03 & 0.06 \\
\hline $\begin{array}{l}\text { Real estate, renting and business } \\
\text { activities }\end{array}$ & 0.06 & 0.06 & 0.07 & 0.11 & 0.10 & 0.13 \\
\hline Education & 0.04 & 0.03 & 0.07 & 0.04 & 0.03 & 0.06 \\
\hline Health and social work & 0.03 & 0.02 & 0.06 & 0.04 & 0.02 & 0.08 \\
\hline $\begin{array}{l}\text { Other social and personal service } \\
\text { activities }\end{array}$ & 0.02 & 0.02 & 0.02 & 0.03 & 0.03 & 0.03 \\
\hline
\end{tabular}


Table B4 Continued

\begin{tabular}{|c|c|c|c|c|c|c|}
\hline & \multicolumn{3}{|c|}{2006} & \multicolumn{3}{|c|}{2014} \\
\hline & All & Males & Females & All & Males & Females \\
\hline \multicolumn{7}{|l|}{ Occupation } \\
\hline Legislators, senior officials, and managers & 0.06 & 0.06 & 0.05 & 0.06 & 0.06 & 0.05 \\
\hline Professionals & 0.08 & 0.06 & 0.13 & 0.12 & 0.10 & 0.16 \\
\hline Technicians and associate professionals & 0.17 & 0.16 & 0.21 & 0.09 & 0.10 & 0.09 \\
\hline Clerks & 0.12 & 0.09 & 0.22 & 0.15 & 0.11 & 0.24 \\
\hline $\begin{array}{l}\text { Service workers; shop and market sales' } \\
\text { workers }\end{array}$ & 0.11 & 0.11 & 0.09 & 0.19 & 0.18 & 0.22 \\
\hline Skilled agricultural and fishery workers & 0.002 & 0.003 & 0.001 & 0.001 & 0.001 & 0.001 \\
\hline Craft and related trade workers & 0.19 & 0.21 & 0.11 & 0.13 & 0.17 & 0.05 \\
\hline $\begin{array}{l}\text { Plant and machine operators and } \\
\text { assemblers }\end{array}$ & 0.13 & 0.15 & 0.06 & 0.13 & 0.15 & 0.07 \\
\hline Elementary occupations & 0.14 & 0.15 & 0.13 & 0.13 & 0.12 & 0.13 \\
\hline \multicolumn{7}{|l|}{ Region } \\
\hline Istanbul & - & - & - & 0.27 & 0.25 & 0.30 \\
\hline West Marmara & - & - & - & 0.07 & 0.07 & 0.07 \\
\hline Aegean & - & - & - & 0.11 & 0.11 & 0.12 \\
\hline East Marmara & - & - & - & 0.12 & 0.12 & 0.10 \\
\hline West Anatolia & - & - & - & 0.10 & 0.10 & 0.11 \\
\hline Mediterranean & - & - & - & 0.09 & 0.09 & 0.08 \\
\hline Central Anatolia & - & - & - & 0.06 & 0.06 & 0.05 \\
\hline West Black Sea & - & - & - & 0.04 & 0.04 & 0.05 \\
\hline East Black Sea & - & - & - & 0.04 & 0.04 & 0.05 \\
\hline Northeast Anatolia & - & - & - & 0.02 & 0.03 & 0.02 \\
\hline Central East Anatolia & - & - & - & 0.03 & 0.04 & 0.03 \\
\hline Southeast Anatolia & - & - & - & 0.04 & 0.05 & 0.04 \\
\hline Number of observations & 241,361 & 175,938 & 65,423 & 132,235 & 91,881 & 40,354 \\
\hline Number of establishments & & 12,874 & & & 7,867 & \\
\hline
\end{tabular}

Data source: Author's calculations based on the SES 2006 and 2014.

Notes: Sample is restricted to individuals of working age (between 15 years old and 64 years old), excluding paid stagers and apprentices, who are employed in establishments that employ both males and females. Region information is only available in 2014 . The data are unweighted. 
Table B5 Sensitivity analysis, BO decomposition of the mean GWG using the female coefficients as the baseline

\begin{tabular}{|c|c|c|c|c|}
\hline & \multicolumn{4}{|c|}{ Specification } \\
\hline & $(2 a)$ & $(2 b)$ & $(2 c)$ & $(2 d)$ \\
\hline \multicolumn{5}{|l|}{2006} \\
\hline \multirow[t]{2}{*}{ Raw GWG } & $0.024^{\star \star \star}$ & $0.024^{\star \star \star}$ & $0.024^{\star \star \star}$ & $0.024^{\star \star \star}$ \\
\hline & $(0.006)$ & $(0.006)$ & $(0.006)$ & $(0.006)$ \\
\hline \multirow[t]{3}{*}{ Explained gap } & $-0.041^{\star \star \star}$ & $-0.031^{\star \star \star}$ & $-0.032^{\star \star \star}$ & $-0.012^{\star \star \star}$ \\
\hline & $(0.003)$ & $(0.004)$ & $(0.005)$ & $(0.001)$ \\
\hline & {$[-174.8 \%]$} & {$[-131.3 \%]$} & {$[-133.6 \%]$} & {$[-48.8 \%]$} \\
\hline \multirow[t]{3}{*}{ Unexplained gap } & $0.065^{\star \star \star}$ & $0.055^{\star \star \star}$ & $0.055^{\star \star \star}$ & $0.035^{\star \star \star}$ \\
\hline & $(0.005)$ & $(0.004)$ & $(0.004)$ & $(0.002)$ \\
\hline & {$[274.8 \%]$} & {$[231.3 \%]$} & [233.6\%] & [148.8\%] \\
\hline \multicolumn{5}{|l|}{2014} \\
\hline \multirow[t]{2}{*}{ Raw GWG } & $0.084^{\star \star \star}$ & $0.084^{\star \star \star}$ & $0.084^{\star \star \star}$ & $0.084^{\star \star \star}$ \\
\hline & $(0.008)$ & $(0.008)$ & $(0.008)$ & $(0.008)$ \\
\hline \multirow[t]{3}{*}{ Explained gap } & $-0.045^{\star \star \star}$ & $-0.024^{\star \star \star}$ & $-0.023^{\star \star \star}$ & 0.001 \\
\hline & $(0.005)$ & $(0.005)$ & $(0.006)$ & $(0.002)$ \\
\hline & {$[-54.1 \%]$} & {$[-28.1 \%]$} & {$[-28.0 \%]$} & {$[1.7 \%]$} \\
\hline \multirow[t]{3}{*}{ Unexplained gap } & $0.129^{\star \star \star}$ & $0.108^{\star \star \star}$ & $0.107^{\star \star \star}$ & $0.083^{\star \star \star}$ \\
\hline & $(0.007)$ & $(0.006)$ & $(0.006)$ & $(0.003)$ \\
\hline & [154.1\%] & [128.1\%] & [128.0\%] & [98.3\%] \\
\hline
\end{tabular}

Data source: Author's calculations based on the SES 2006 and 2014.

Notes: (i) Sample is restricted to individuals of working age (between 15 years old and 64 years old), excluding paid stagers and apprentices, who are employed in establishments that employ both males and females. The data are not weighted. (ii) Figures in () are establishment level clustered standard errors. (iii) ${ }^{\star},{ }^{\star \star}$, and ${ }^{\star \star \star}$ denote significance at 0.001, 0.01, and 0.05 significance levels, respectively. (iv) BO method is used to decompose the mean GWG using relevant female coefficients as the baseline. (v) Specifications (2a)-(2d) are as set out in the text. (vi) Figures in [] are proportions of the raw GWG.

BO, Blinder-Oaxaca; GWG, gender wage gap; SES, Structure of Earnings Survey. 
Table B6 Components of the BO decomposition of the mean GWG, 2006

\begin{tabular}{|c|c|c|c|c|}
\hline & \multicolumn{4}{|c|}{ Specification } \\
\hline & (2a) & (2b) & (2c) & $(2 d)$ \\
\hline \multirow[t]{2}{*}{ Raw GWG } & $0.024^{\star \star \star}$ & $0.024^{\star \star \star}$ & $0.024^{\star \star \star}$ & $0.024^{\star \star \star}$ \\
\hline & $(0.006)$ & $(0.006)$ & $(0.006)$ & $(0.006)$ \\
\hline \multirow[t]{3}{*}{ Explained gap } & $-0.023^{\star \star \star}$ & $-0.025^{\star \star \star}$ & $-0.024^{\star \star \star}$ & $-0.016^{\star \star \star}$ \\
\hline & $(0.003)$ & $(0.004)$ & $(0.005)$ & $(0.001)$ \\
\hline & {$[-97.2]$} & {$[-104.8 \%]$} & {$[-103.1 \%]$} & {$[-65.9 \%]$} \\
\hline \multirow[t]{2}{*}{ Unexplained gap } & $0.047^{\star \star \star}$ & $0.049 * \star \star$ & $0.048^{\star \star \star}$ & $0.039^{\star \star \star}$ \\
\hline & $(0.005)$ & $(0.004)$ & $(0.004)$ & $(0.001)$ \\
\hline Explained & [197.2] & [204.8\%] & [203.1\%] & [165.9\%] \\
\hline \multicolumn{5}{|l|}{ Personal characteristics } \\
\hline \multirow[t]{3}{*}{ Education } & $-0.138^{\star \star \star}$ & $-0.119^{\star \star \star}$ & $-0.106^{\star \star \star}$ & $-0.067^{\star \star \star}$ \\
\hline & $(0.004)$ & $(0.003)$ & $(0.003)$ & $(0.001)$ \\
\hline & {$[-580.0 \%]$} & {$[-503.1 \%]$} & {$[-447.8 \%]$} & {$[-282.4 \%]$} \\
\hline \multirow{3}{*}{$\begin{array}{l}\text { Potential labour market } \\
\text { experience }\end{array}$} & $0.115^{\star \star \star}$ & $0.054^{\star \star \star}$ & $0.054^{\star \star \star}$ & $0.046^{\star \star \star}$ \\
\hline & $(0.003)$ & $(0.002)$ & $(0.002)$ & $(0.001)$ \\
\hline & [482.8\%] & [225.8\%] & [227.7\%] & [192.1\%] \\
\hline \multicolumn{5}{|l|}{ Work-related characteristics } \\
\hline \multirow[t]{3}{*}{ Tenure } & & $0.038^{\star \star \star}$ & $0.024^{\star \star \star}$ & $0.016^{\star \star \star}$ \\
\hline & & $(0.002)$ & $(0.002)$ & $(0.000)$ \\
\hline & & {$[160.6 \%]$} & {$[101.1 \%]$} & [68.7\%] \\
\hline \multirow[t]{3}{*}{ Permanent contract } & & 0.000 & -0.000 & $-0.000^{\star \star \star}$ \\
\hline & & $(0.000)$ & $(0.000)$ & $(0.000)$ \\
\hline & & {$[0.6 \%]$} & {$[-0.8 \%]$} & {$[-0.8 \%]$} \\
\hline \multirow[t]{3}{*}{ Full-time } & & $-0.005^{\star \star \star}$ & $-0.006^{\star \star \star}$ & $-0.006^{\star \star \star}$ \\
\hline & & $(0.001)$ & $(0.001)$ & $(0.000)$ \\
\hline & & {$[-20.3 \%]$} & {$[-23.8 \%]$} & {$[-24.5 \%]$} \\
\hline \multirow[t]{3}{*}{ Overtime work } & & $0.007^{\star \star \star}$ & $0.003^{\star \star \star}$ & $-0.005^{\star \star \star}$ \\
\hline & & $(0.001)$ & $(0.000)$ & $(0.000)$ \\
\hline & & {$[31.4 \%]$} & {$[12.7 \%]$} & {$[-19.1 \%]$} \\
\hline \multicolumn{5}{|l|}{$\begin{array}{l}\text { Observed firm and establishment } \\
\text { characteristics }\end{array}$} \\
\hline \multirow[t]{3}{*}{ Firm size } & & & 0.001 & \\
\hline & & & $(0.001)$ & \\
\hline & & & [3.9\%] & \\
\hline \multirow[t]{3}{*}{ Collective agreement coverage } & & & $0.012^{\star \star \star}$ & \\
\hline & & & $(0.001)$ & \\
\hline & & & {$[49.3 \%]$} & \\
\hline \multirow[t]{2}{*}{ Industry of the establishment } & & & $-0.006^{\star}$ & \\
\hline & & & $(0.002)$ & \\
\hline Unexplained & & & {$[-25.5 \%]$} & \\
\hline Characteristics & 0.006 & -0.010 & -0.031 & $0.056^{\star \star}$ \\
\hline
\end{tabular}


Table B6 Continued

\begin{tabular}{lcccc}
\hline & \multicolumn{4}{c}{ Specification } \\
\cline { 2 - 5 } & $\mathbf{( 2 \mathbf { a } )}$ & $\mathbf{( 2 \mathbf { b } )}$ & $\mathbf{( 2 \mathbf { c } )}$ & $\mathbf{( 2 \mathbf { d } )}$ \\
\hline \multirow{3}{*}{ Constant } & $(0.011)$ & $(0.051)$ & $(0.051)$ & $(0.022)$ \\
& {$[26.3 \%]$} & {$[-42.8 \%]$} & {$[-132.1 \%]$} & {$[237.8 \%]$} \\
& $0.041^{\star \star \star}$ & 0.059 & 0.080 & -0.017 \\
& $(0.010)$ & $(0.051)$ & $(0.052)$ & $(0.022)$ \\
& {$[170.9 \%]$} & {$[247.6 \%]$} & {$[335.2 \%]$} & {$[-71.9 \%]$} \\
\hline
\end{tabular}

Data source: Author's calculations based on the SES 2014.

Notes: (i) Figures in () are establishment level clustered standard errors. Figures in [] are proportions of the raw GWG. (ii) ${ }^{\star}$, ${ }^{\star \star}$, and ${ }^{* \star \star}$ denote significance at $0.001,0.01$, and 0.05 significance levels, respectively. (iii) BO method is used to decompose the mean raw GWG using relevant male coefficients as the baseline. (iv) Specifications (2a)-(2d) are as set out in the text. The reported constant in Specification (2d) is the gender difference in average value of the establishment fixed effects capturing the unobserved establishment heterogeneity. BO, Blinder-Oaxaca; GWG, gender wage gap; SES, Structure of Earnings Survey. 
Table B7 Components of the BO decomposition of the mean GWG, 2014

\begin{tabular}{|c|c|c|c|c|}
\hline & \multicolumn{4}{|c|}{ Specification } \\
\hline & (2a) & $(2 b)$ & (2c) & $(2 d)$ \\
\hline \multirow[t]{2}{*}{ Raw GWG } & $0.084^{\star \star \star}$ & $0.084^{\star \star \star}$ & $0.084^{\star \star \star}$ & $0.084^{\star \star \star}$ \\
\hline & $(0.008)$ & $(0.008)$ & $(0.008)$ & $(0.003)$ \\
\hline \multirow[t]{3}{*}{ Explained gap } & $-0.035^{\star \star \star}$ & $-0.024^{\star \star \star}$ & $-0.019^{\star \star \star}$ & $-0.008^{\star \star \star}$ \\
\hline & $(0.005)$ & $(0.005)$ & $(0.006)$ & $(0.002)$ \\
\hline & {$[-41.9 \%]$} & {$[-29.1 \%]$} & {$[-22.8 \%]$} & {$[-9.0 \%]$} \\
\hline \multirow[t]{2}{*}{ Unexplained gap } & $0.119^{\star \star \star}$ & $0.108^{\star \star \star}$ & $0.103^{\star \star \star}$ & $0.092^{\star \star \star}$ \\
\hline & $(0.007)$ & $(0.006)$ & $(0.006)$ & $(0.003)$ \\
\hline Explained & [141.9\%] & [129.1\%] & {$[122.8 \%]$} & {$[109.0 \%]$} \\
\hline \multicolumn{5}{|l|}{ Personal characteristics } \\
\hline \multirow[t]{3}{*}{ Education } & $-0.115^{\star \star \star}$ & $-0.109^{\star \star \star}$ & $-0.101^{\star \star \star}$ & $-0.066^{\star \star \star}$ \\
\hline & $(0.005)$ & $(0.005)$ & $(0.004)$ & $(0.002)$ \\
\hline & {$[-137.0 \%]$} & {$[-129.6 \%]$} & {$[-119.7 \%]$} & {$[-79.2 \%]$} \\
\hline \multirow{3}{*}{$\begin{array}{l}\text { Potential labour market } \\
\text { experience }\end{array}$} & $0.080^{\star \star \star}$ & $0.051^{\star \star \star}$ & $0.054^{\star \star \star}$ & $0.045^{\star \star \star}$ \\
\hline & $(0.003)$ & $(0.002)$ & $(0.002)$ & $(0.001)$ \\
\hline & [95.2\%] & {$[61.2 \%]$} & [64.9\%] & {$[54.0 \%]$} \\
\hline \multicolumn{5}{|l|}{ Work-related characteristics } \\
\hline \multirow[t]{3}{*}{ Tenure } & & $0.028^{\star \star \star}$ & $0.023^{\star \star \star}$ & $0.017^{\star \star \star}$ \\
\hline & & $(0.002)$ & $(0.002)$ & $(0.001)$ \\
\hline & & [33.5\%] & [27.0\%] & [20.6\%] \\
\hline \multirow[t]{3}{*}{ Permanent contract } & & 0.000 & 0.000 & 0.000 \\
\hline & & $(0.001)$ & $(0.001)$ & $(0.000)$ \\
\hline & & [0.3\%] & {$[0.3 \%]$} & [0.6\%] \\
\hline \multirow[t]{3}{*}{ Full-time } & & -0.000 & -0.000 & $-0.001^{\star \star \star}$ \\
\hline & & $(0.000)$ & $(0.000)$ & $(0.000)$ \\
\hline & & {$[-0.3 \%]$} & {$[-0.3 \%]$} & {$[-1.3 \%]$} \\
\hline \multirow[t]{3}{*}{ Overtime work } & & $0.005^{\star \star \star}$ & -0.001 & $-0.003^{\star \star \star}$ \\
\hline & & $(0.001)$ & $(0.001)$ & $(0.000)$ \\
\hline & & [5.8\%] & {$[-1.2 \%]$} & {$[-3.7 \%]$} \\
\hline \multicolumn{5}{|l|}{$\begin{array}{l}\text { Observed firm and establishment } \\
\text { characteristics }\end{array}$} \\
\hline \multirow[t]{3}{*}{ Firm size } & & & -0.002 & \\
\hline & & & $(0.002)$ & \\
\hline & & & {$[-1.9 \%]$} & \\
\hline \multirow[t]{3}{*}{ Collective agreement coverage } & & & $0.003^{\star \star \star}$ & \\
\hline & & & $(0.001)$ & \\
\hline & & & {$[3.8 \%]$} & \\
\hline \multirow[t]{2}{*}{ Industry of the establishment } & & & 0.004 & \\
\hline & & & $(0.003)$ & \\
\hline Unexplained & & & [4.3\%] & \\
\hline
\end{tabular}


Table B7 Continued

\begin{tabular}{lcccc}
\hline & \multicolumn{4}{c}{ Specification } \\
\cline { 2 - 5 } & $\mathbf{( 2 a )}$ & $\mathbf{( 2 b )}$ & $\mathbf{( 2 \mathbf { c } )}$ & $\mathbf{( 2 d )}$ \\
\hline Characteristics & $0.054^{\star \star}$ & $0.133^{\star}$ & 0.072 & $0.110^{\star \star}$ \\
& $(0.017)$ & $(0.056)$ & $(0.059)$ & $(0.033)$ \\
Constant & {$[64.0 \%]$} & {$[157.9 \%]$} & {$[85.6 \%]$} & {$[130.8 \%]$} \\
& $0.065^{\star \star \star}$ & -0.024 & 0.031 & -0.018 \\
& $(0.018)$ & $(0.057)$ & $(0.060)$ & $(0.033)$ \\
& {$[77.8 \%]$} & {$[-28.8 \%]$} & {$[37.2 \%]$} & {$[-21.8 \%]$} \\
\hline
\end{tabular}

Data source: Author's calculations based on the SES 2014.

Notes: (i) Figures in () are establishment level clustered standard errors. Figures in [] are proportions of the raw GWG. (ii) ${ }^{\star}$, ${ }^{\star *}$, and ${ }^{* \star *}$ denote significance at $0.001,0.01$, and 0.05 significance levels, respectively. (iii) BO method is used to decompose the mean raw GWG using relevant male coefficients as the baseline. (iv) Specifications (2a)-(2d) are as set out in the text. The reported constant in Specification (2d) is the gender difference in average value of the establishment fixed effects capturing the contribution of unobserved establishment heterogeneity.

BO, Blinder-Oaxaca; GWG, gender wage gap; SES, Structure of Earnings Survey. 


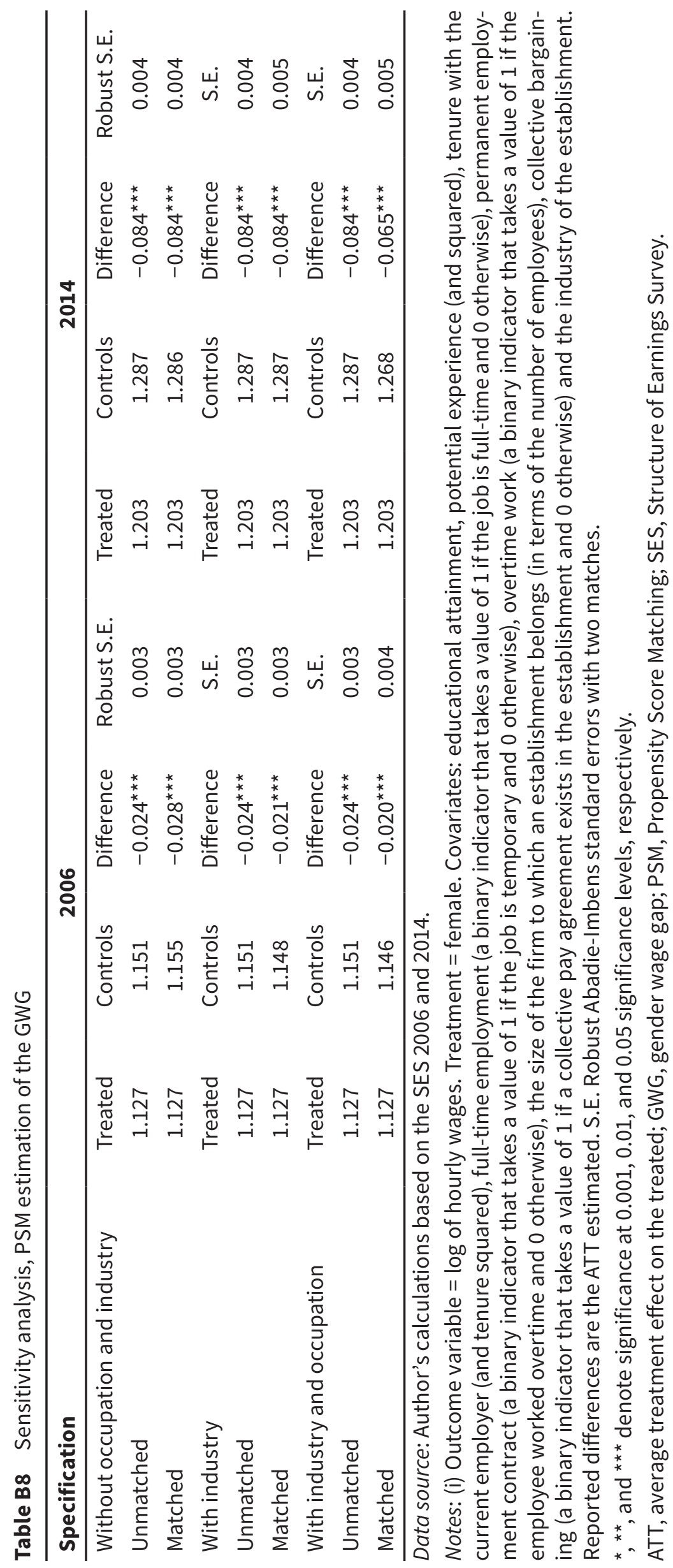




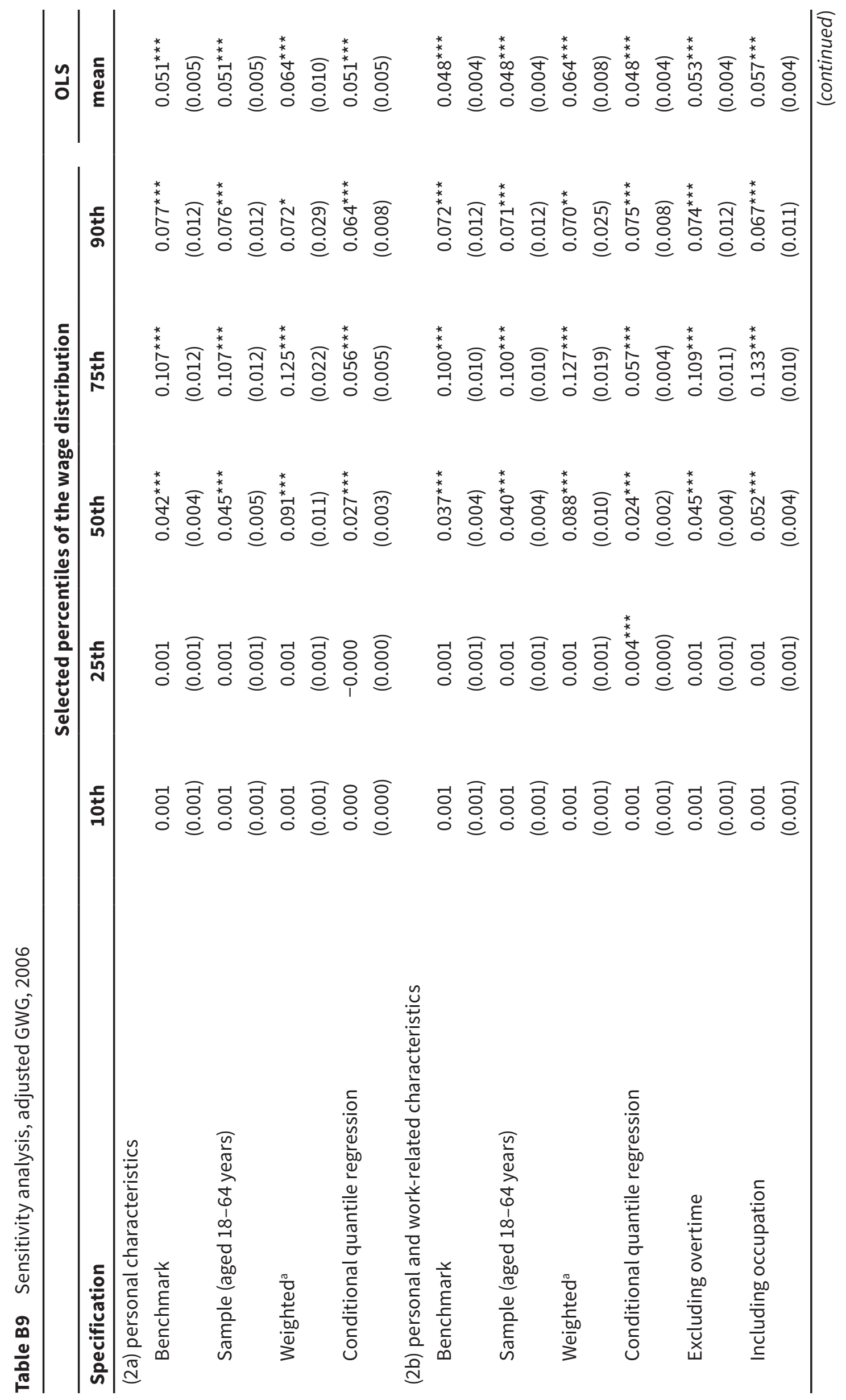




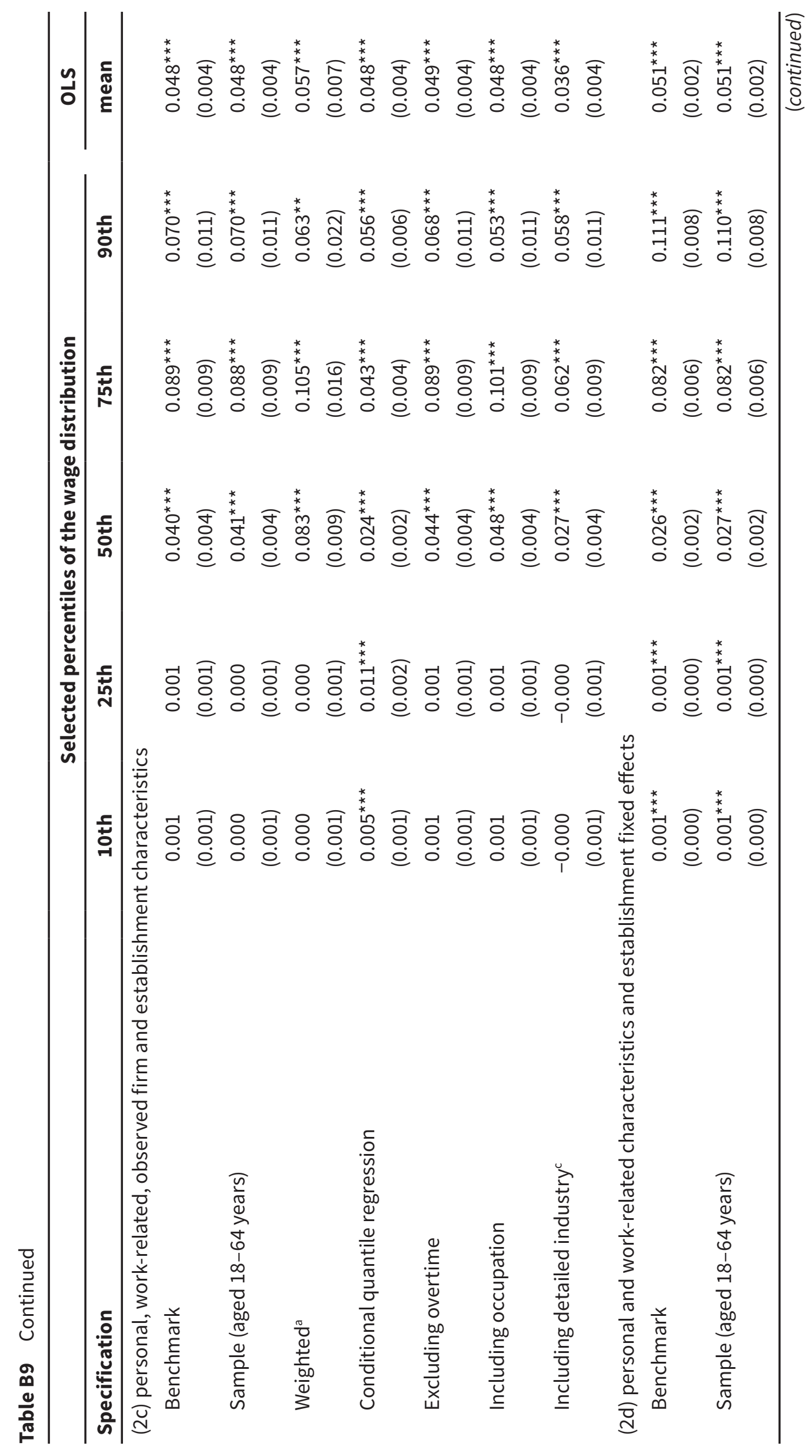




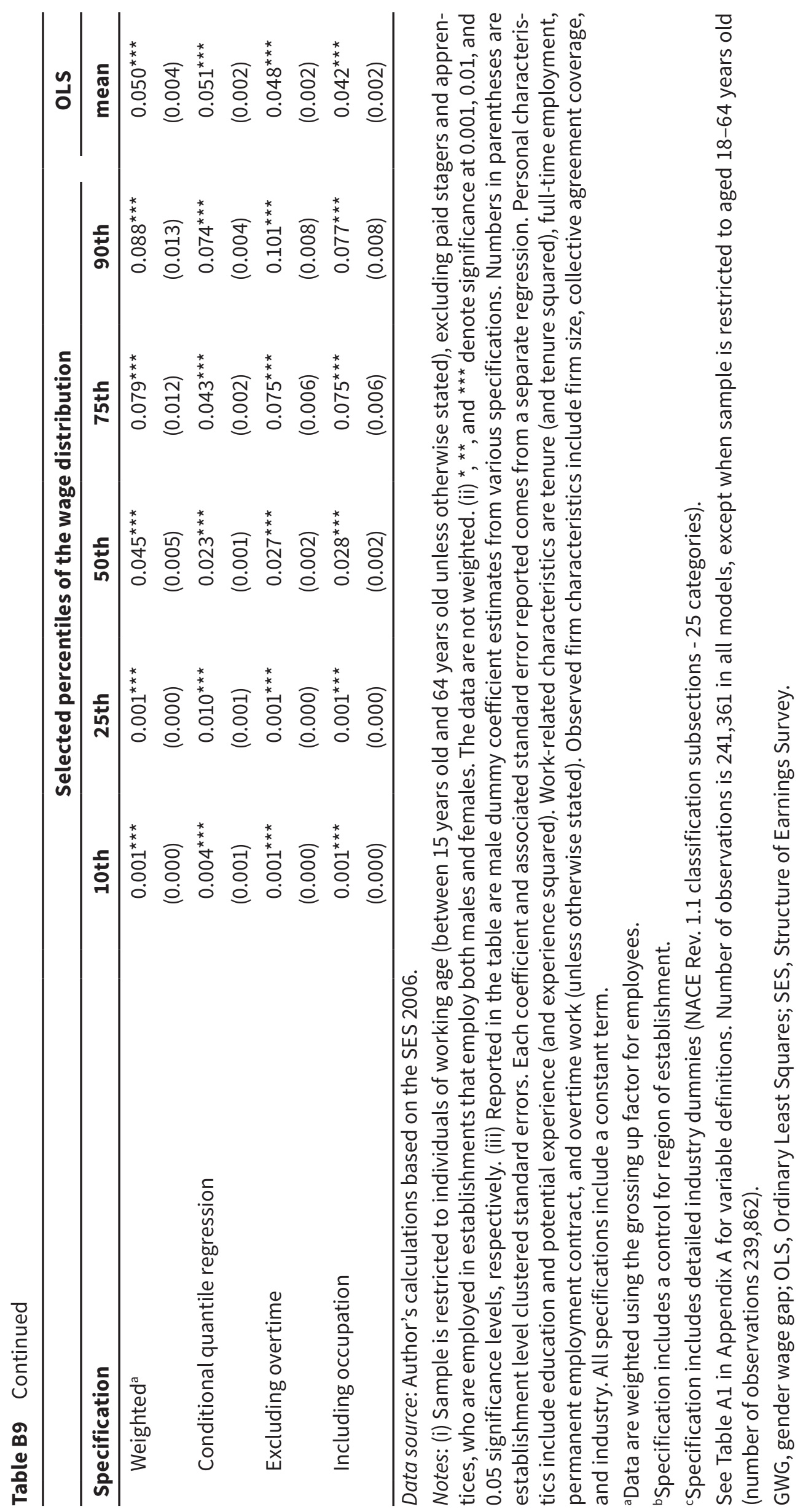




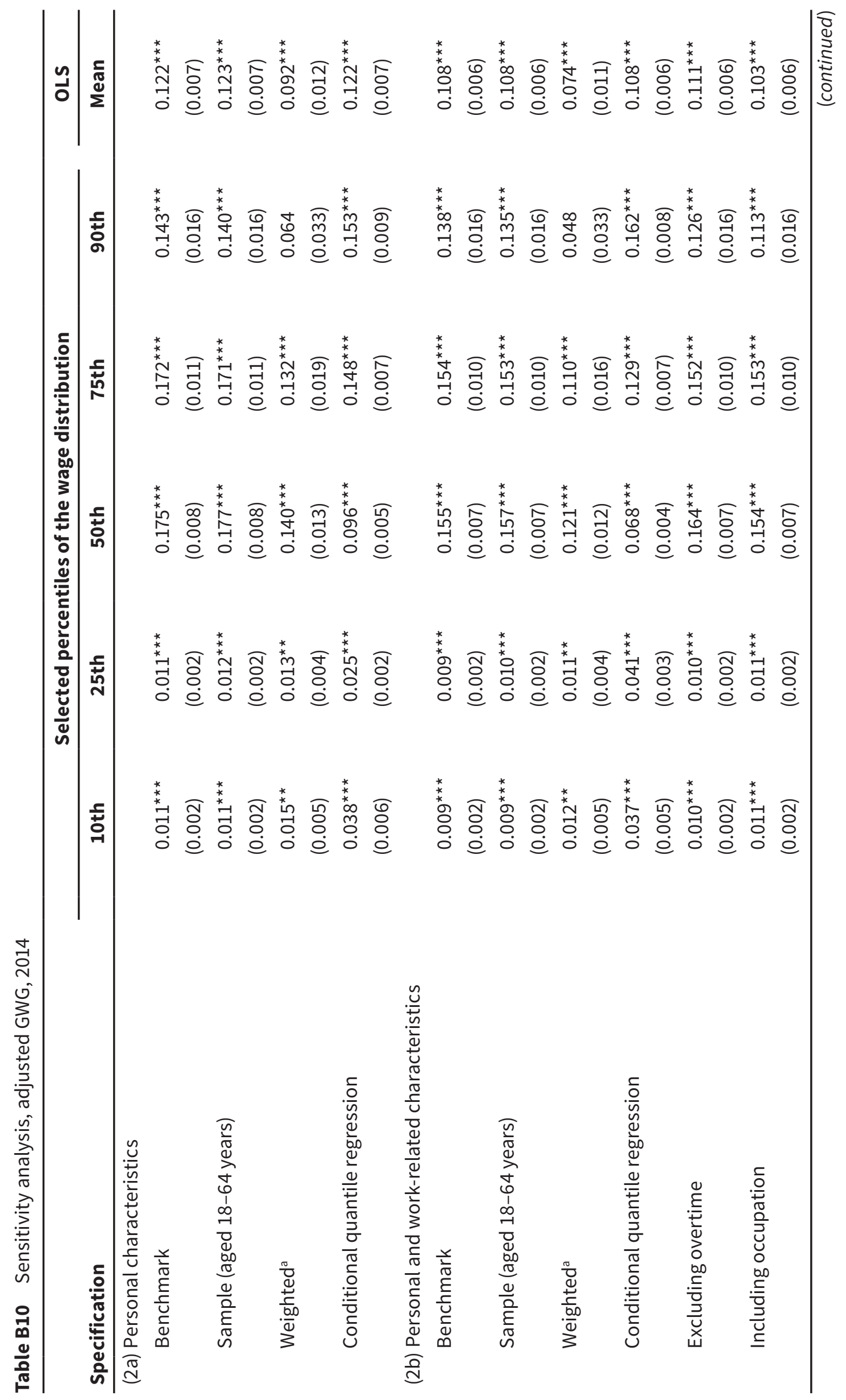




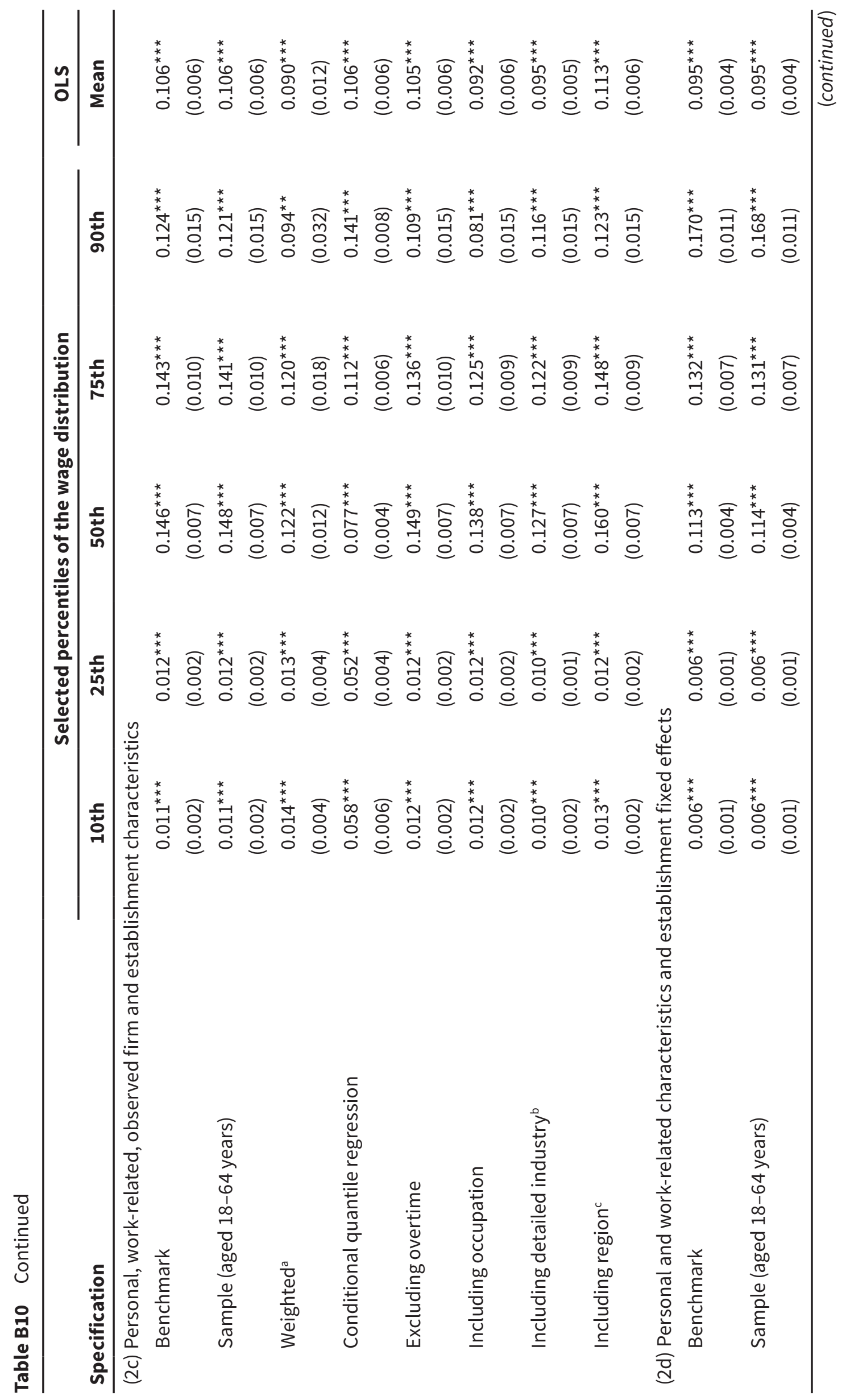




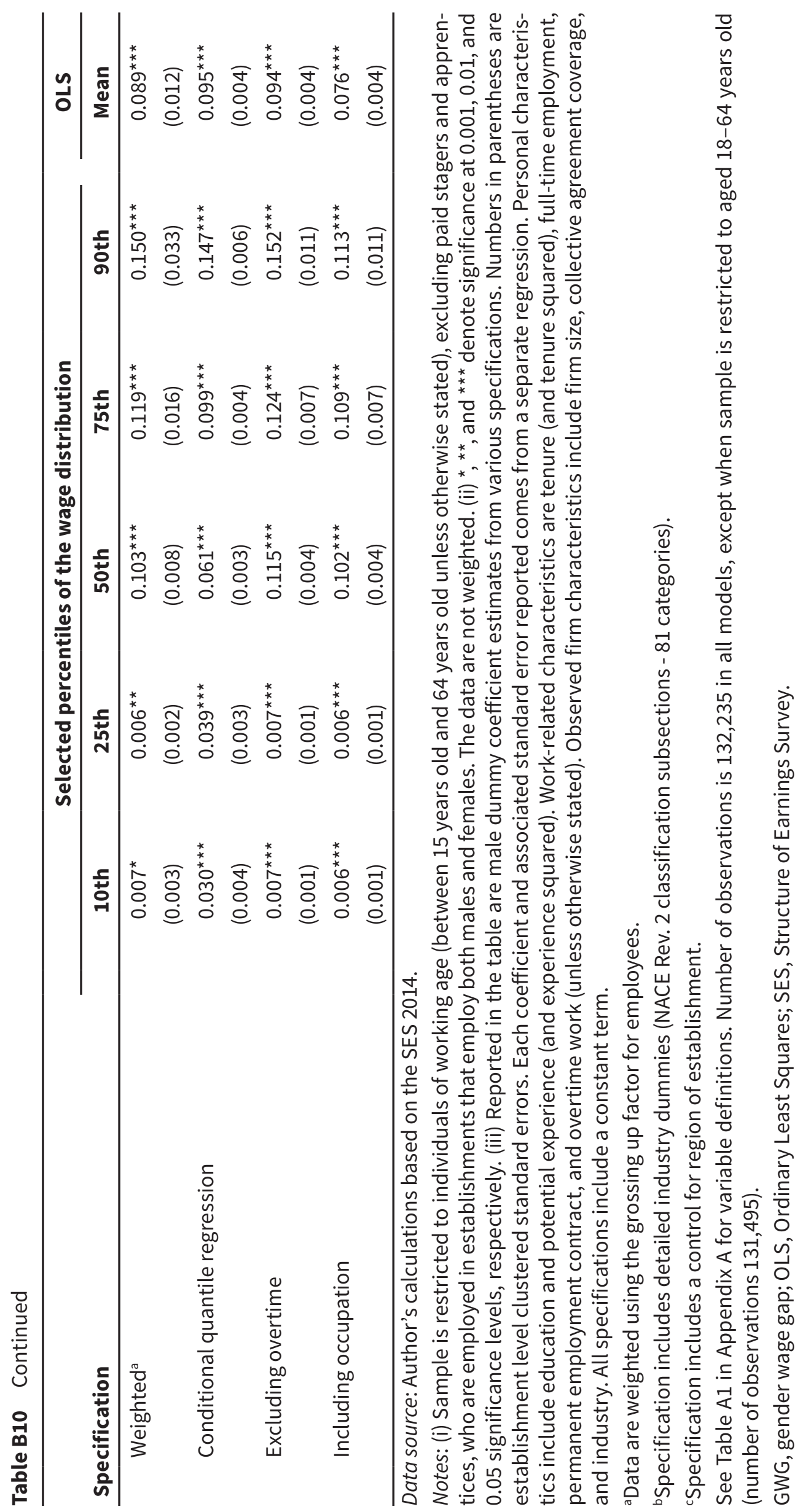


Figure B1 Sensitivity analysis, MM decomposition of the GWG across the distribution, 2006.

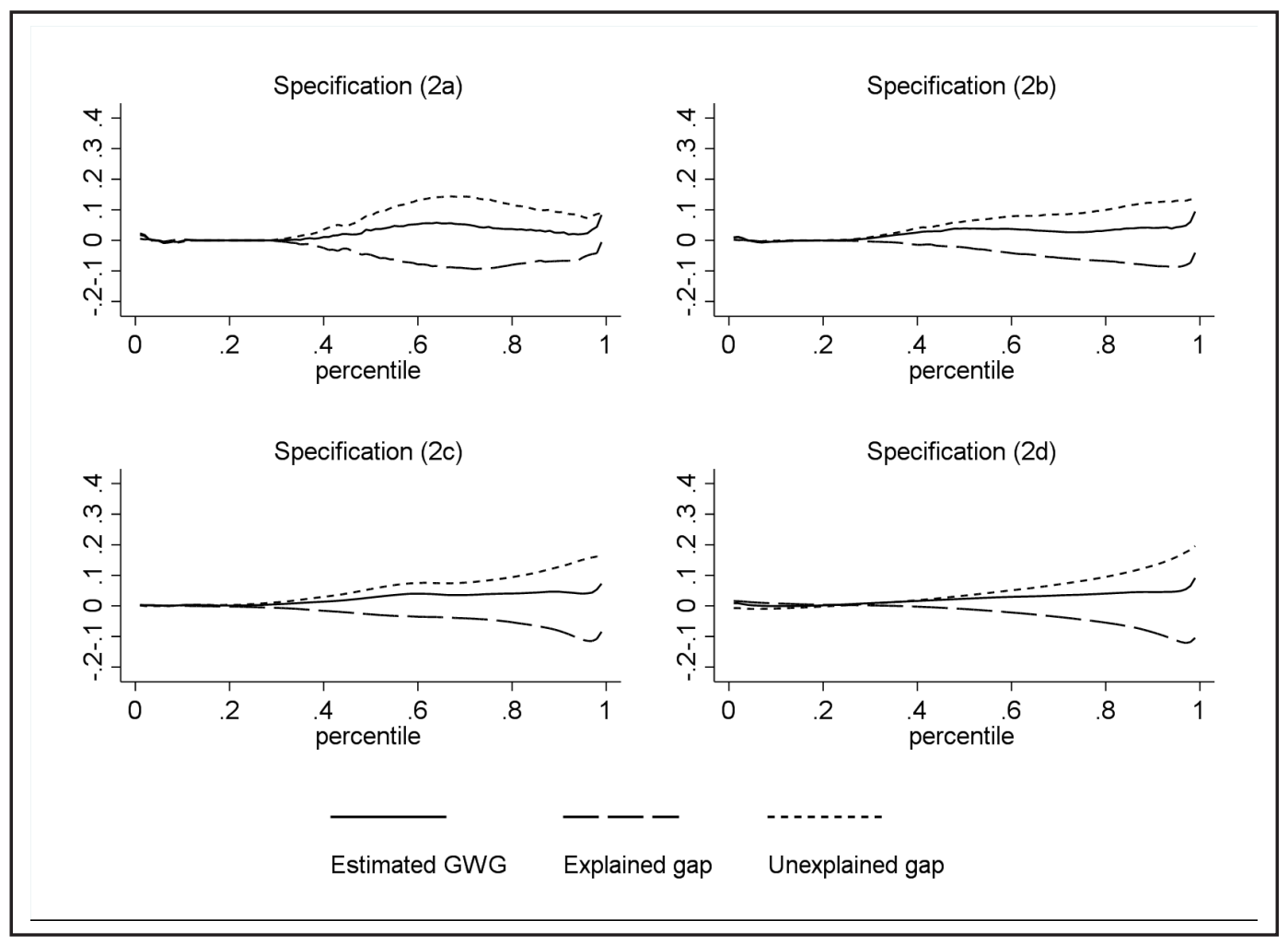

Data source: Author's calculations based on the SES 2006.

Notes: (i) Specifications (2a)-(2d) are as set out in the text. (ii) MM decomposition method is used to decompose the GWG using male coefficients as the baseline. (iii) "Estimated GWG" is the estimated raw GWG using the conditional quantile regression model and integrating over the set of covariates. "Explained gap" is that part of the observed gap that is due to gender differences in productivity-related characteristics included in the specification. "Unexplained gap" is that part of the observed gap that remains unexplained after controlling for the productivity-related characteristics. GWG, gender wage gap; MM, Machado-Mata; SES, Structure of Earnings Survey. 
Figure B2 Sensitivity analysis, MM decomposition of the GWG across the distribution, 2014.

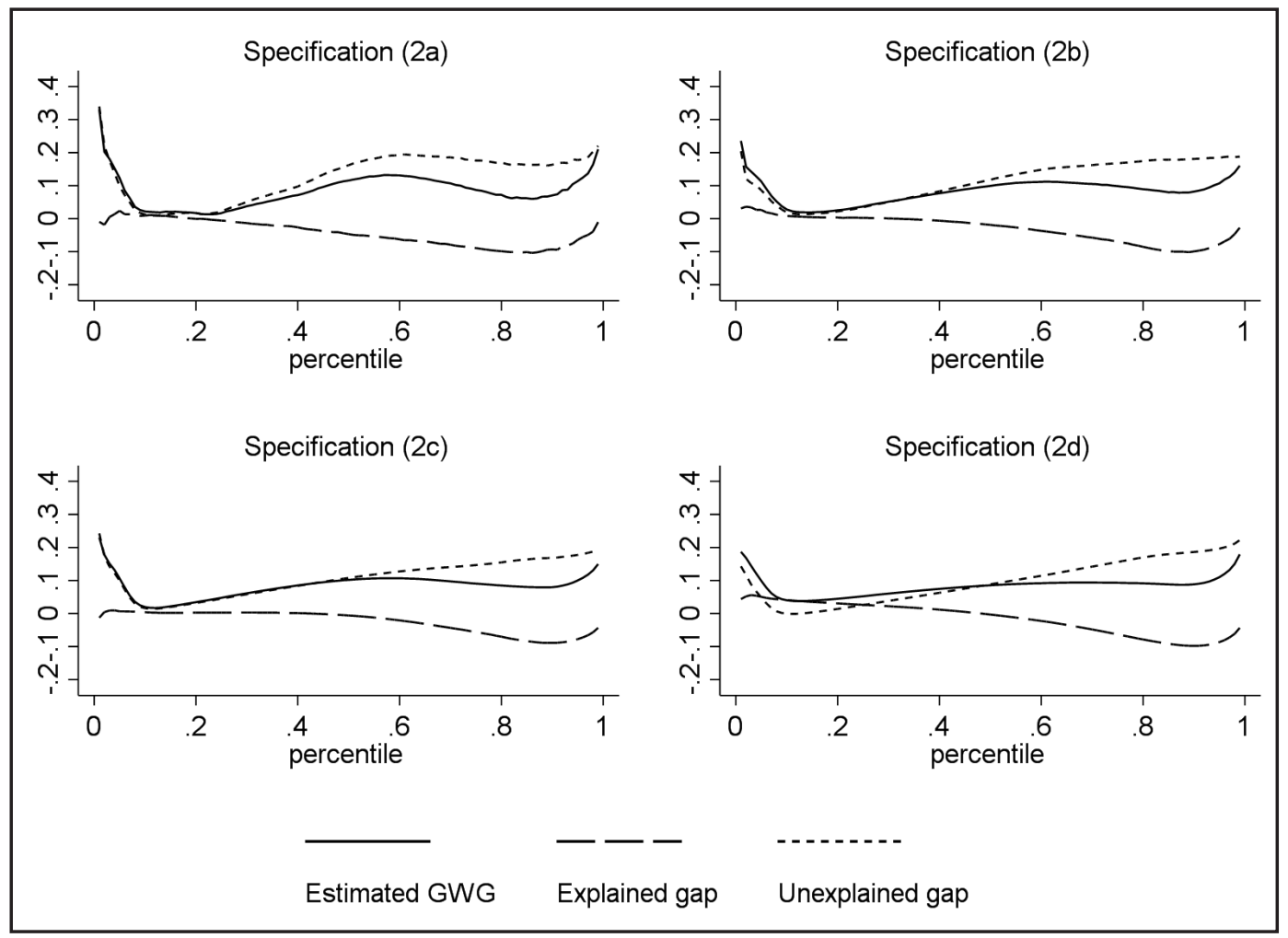

Data source: Author's calculations based on the SES 2014.

Notes: (i) Specifications (2a)-(2d) are as set out in the text. (ii) MM decomposition method is used to decompose the GWG using male coefficients as the baseline. (iii) "Estimated GWG" is the estimated raw GWG using the conditional quantile regression model and integrating over the set of covariates. "Explained gap" is that part of the observed gap that is due to gender differences in productivity-related characteristics included in the specification. "Unexplained gap" is that part of the observed gap that remains unexplained after controlling for the productivity-related characteristics. GWG, gender wage gap; MM, Machado-Mata; SES, Structure of Earnings Survey. 